\title{
Index for Volume 92
}

AUTHOR AND SUBJECT INDEX. Pages indicating errata are in italic. "S" indicates supplement pages. "A" indicates abstract not included in supplement. Publication number P-2002-1028-01O.

Abad, J. A., S1, 1026, S59

Abad, Z. G., S1, 1026

Abadias, M., 281

Abawi, G. S., S62

Abbas, H. K., S1, S87

Abbasi, P. A., S1

Abbo, S., 417

Abies concolor, dwarf mistletoe interaction, in Sierra Nevada, 597

Abney, T. S., S39

Abreu, D., S131

Abril, M., 1055

Abstracts

- annual meeting, $\mathrm{S} 1$

- Caribbean Division, S114

- North Central Division, S137

- Northeastern and Potomac Divisions, S142

- Southern Division, S148

Abt, J. J., 1167

Abu-El Samen, F. M., S137

Accotto, G. P., S132, S136

Acevedo, R., S114, S125, S132

Achor, D., A1024

Acidovorax avenae

—on corn and rice, phylogeny, S66

-on watermelon: chemical and insertional mutagenesis, S57; new in Illinois, S5; seed infection, S84

Ackerman, J., 1167

Acremonium implicatum, on Brachiaria, endophytic, detection, S41

Adams, G. C., S1, S7

Adams, K., S64

Adaskaveg, J. E., S2, S19, S20, S26

Adela Santos, M., S119

Adhikari, T., S2

Adkins, S., S2, A1024

Aerobiology, spore dispersal across spatial scales, S97

Afunian, M., S2

Agama, K., 190, S46

Agarkova, I. V., S2

Agramonte, D., S125

Agrobacterium tumefaciens

-interactions on inert and plant surfaces, S97

-ros gene, $\mathrm{S} 84$

Aguiar, E., S119, S131

Aguilar Ríos, J., S123, S132

Aguilar, E., S119, S127

Ahlers, C. A., S145, S146

Ahmed, H. U., S18

Aisa, P. H., S2

Aist, J. R., 900

Ajwa, H. A., 1349

Akimitsu, K., 794, S7

Akinsanmi, O. A., S2

Alabouvette, C., 936

Alameda, M., S114

Albano, J. P., S71

Alberte, R. S., 378

Alcino da Silva, J., S118, S132

Alderman, S. C., S52

Alexander, S. A., S142

Alfalfa

-Aphanomyces euteiches, PCR assay, quantification, 265

—Pythium spp., biocontrol by Pseudomonas, S3

- Sclerotinia trifoliorum, effect on Sclerotium rolfsii resistance, 204

-witches'-broom, new phytoplasma, in Oman, 1038

Alfalfa mosaic virus

—on snap bean, reaction, S140 -on soybean, chimeric rabies peptide, letter to editor, 1260

Alfano, J. R., S102

Alfenas, A. C., S122

Alfonso, I., S132

Alfonso-Rubí, J., S114, S119, S131

Ali, S., 38, S3

Alkowni, R., S3

Alleman, R. J., S137

Allen, C., S3

Allen, J. B., S3

Allen, T. W., Jr., S148

Alleyne, A. T., S3

Allison, K., A1025

Almándoz, J., S114

Almeida, R. P. P., S3

Almond, leaf scorch, leafhopper transmission, S3

Alonso, M., S115

Al-Saadi, A., S3

Al-Subhi, A. M., 1038

Alteri, C., 734

Alternaria spp.: Astragalus and Oxytropis, seed tissue and toxicity, S70; on pistachio, molecular characterization of isolates, 406; phylogenetic relation, Embellisia and Nimbya, S7

-A. alternata, on citrus: ecology, S7; phylogeography worldwide, 794

-A. brassicicola, on Arabidopsis thaliana: interaction using functional genomics, S45; pathogenesis genes, S17

$-A$. porri, on onion, resistance induction in greenhouse, $\mathrm{S} 4$

-A. solani, on tomato, control factors, S130

Altier, N., S3

Alvares, Y., S133

Alvarez, A. M., S4, S27

Alvarez, C., S131

Alves-Santos, F. M., 237

Amaranth, Pythium stem canker, S8

Ambrozio, M. R., S82

Amedeo, P., S102

American Phytopathological Society

- annual report, 15

-extension award, 25

-fellows, 19

-industry award, 26

-international sevice award, 28

- Lee Hutchins award, 29

—officers, representatives, and committees, 13

—presidential address, Slack, 17

-Ruth Allen award, 30

- Syngenta award, 31

- teaching award, 27

Ammermann, E., S4, S79

Amsellem, Z., 590

Anas, O., S35

Anders, M., S56

Andersen, R. L., S33

Anderson, A. J., S38, S51

Anderson, J. A., 527

Anderson, J. M., S2, S5, S68

Anderson, M., S141

Anderson, P. K., S109

Anderson, R. J., 1167

Andrews, D. L., S27

Andrews, J. A., S53

Andrews, J. H., S78

Andrie, R. M., S51

Andropogon gerardii, in tallgrass prairie, spring burning and fungicide effect, S58

Animal and Plant Health Inspection Service, careers in, S112

Annis, S. L., S64
Anthurium

-blight, detection by bacteria, S4

- transgenic, peptide effect on bacteria, S27

Antibiotics, bacterial diseases, future, $\mathrm{S} 107$

Apel-Birkhold, P. C., 833

Aphanomyces spp.

-A. cochlioides: green manure and soil solarization, S9; oospores, modeling survival, S22

$-A$. euteiches on alfalfa, PCR assay to quantify, 265; on pea, resistance gene detection, S138

Aphis glycines, on soybean, transmission by Alfalfa mosaic and Clover yellow mosaic viruses, $\mathrm{S} 137$

Appel, D., S4

Apple

-blister rot, diagnosis with PCR, hrpL gene primers, 1077

-blue mold, disease control agents induce resistance, 900

—blue mold and bitter rot, control strategy, S46

- canopy, leaf wetness duration variation, S6

-Colletotrichum acutatum, calcium chloride effect, S63

-discrete speck, sooty blotch and flyspeck complex, S6

- disease control program, trifloxystrobin and kresoxim-methyl, S146

-fire blight: bentamicin for, S55; biocontrol with Pantoea agglomerans, 1202; gentamicin for control, health implications, S87; Hedera helix extract effect, S115; new antibiotic formulation, tests, S54; plant growth regulators, S108; prohexadione-Ca effectiveness, S147

- postharvest, Penicillium expansum, fludioxonil, S145

-postharvest disease, biocontrol with Muscodor albus, S55

- powdery mildew, incidence and density relations, 1005

-scab: ascospore distribution in orchards, 769; genes as resistant locus, $\mathrm{S} 2$

— shoot blight, streptomycin sulfate efficacy, S60

- sooty blotch and flyspeck complex: fungicide effects, S6; ribosomal DNA, S6; warning system, wetness effects, S29

Arabidopsis spp.: bacterial wilt, ethylene-insensitive mutant, symptom delay, 1142; hypersensitive response cell death, loss, S103; Pseudomonas on, general resistance, $\mathrm{S} 138$

-A. thaliana: Cauliflower mosaic virus, resistance breakage, 190; fungal pathogens, analysis, S103; Streptomyces spp., endophytic colonization, S16

Arachis spp., root-knot, resistance in interspecific hybrids, S15

Aranda, M. A., 842

Araújo, W., L., 1048

Arboleya, J., S4

Arceuthobium spp., host interaction in mixedconifer forests, Sierra Nevada, 597

Arencibia, A., S120, S121, S122, S133

Arene, L., 314

Arias, A., S3

Arias, G. G., S122

Armas, R., S119, S131

Armillaria spp.: ecological behavior in population, S95; prescribed burning effects, S39

$-A$. tabescens, phenotypic and genotypic variation in isolates, $\mathrm{S} 73$

Arnason, J. T., S7

Arocha, Y., S115

Arora, N., S58

Arrebola, E., 909 
Arroyo Cordero, F. T., S117

Arsenovic, M., S80

Arthrobotrys oligospora

-on putting green soil, chlorothalonil for, S153

- putting greens, parasitic nematode reduction by, $\mathrm{S} 88$

Arunyanart, P., S110

Arzola, M., S117, S133

Asparagus, Fusarium infection, salicylic acid effect, S35

Aspergillus spp., aflatoxin production, in Mississippi, S1

-A. flavus: aflatoxin biosynthesis, mutation, S37; on corn, endosperm protein, S15; on corn, granular application for inoculation, S87; wild type and mutant analysis, gene expression, S73 -A. nidulans, sterigmatocystin biosynthesis, $\mathrm{S} 91$

- A. niger, on onion, endophyte, S82

Assaraf, M. P., 956

Assis Filho, F. M. de, 729, S4

Astley, D., 105

Atkinson, H., S76

Attard, A., 1122

Aureobasidium pullulans

-on apple, leaf growth pattern, S53

—on apple leaves, population biology, S78

Author index, abstracts, S154

Avant, J. B., 1055

Avila, F. J., S4

Avila-Adame, C., S61

Avilán, L., S128

Avocado, Colletotrichum gloeosporioides, fruit protection mechanisms, analysis, 1196

Axtell, C. A., S97

Ayers, J. E., 232

Aylor, D. E., S97

Ayra-Pardo, C., S132

Azad, H. R., S82

Azevedo, J. L., 464

Baayen, R. P., 464, S46

Babadoost, M., S5, S29, S38

Bacillus spp.

$-B$. mojavensis, biocontrol agent, ribotyping, A1024

-B. mycoides, on strawberry, biocontrol agent, 976

$-B$. subtilis, bean root rot controlled by, crop residue effect, $\mathrm{S} 24$

Backhouse, D., S2

Bacon, C. W., A1024

Bacteria

- crop diseases, field diagnosis, portable tealtime PCR, S72

—detection, rapid PCR preparation, S54

- detection by real-time PCR, S110

- leaf surface colonization, water role, S97

Bacterial diseases

-field diagnosis, real-time PCR, S110

-PCR technology, review, S110

Bacteriophage, tomato bacterial spot controlled by, $\mathrm{S} 6$

Bahadur Meah, M., S124

Bahk, K. K., S5

Bai, X., S5

Bailey, B. A., 833, 1032, S83

Bailey, J. E., S64

Baird, R. E., 893

Bajsa, N., S3

Baker, C. A., S111

Baker, C. J., S40, S48, S69, S122

Baker, S. E., S102

Balagué, C., 1142

Balaji, B., S5

Balbyshev, N., S140

Balconi, C., S28

Baldo, A. M., S102

Bales, S., S111

Balesdent, M. H., 1122
Bally, R., S69

Balogh, B., S6, S60, S108

Banana

-biotechnology and practice in Cuba, S125

-black sigatoka disease: management, S135; toxins for selection, $\mathrm{S} 132$

-crown rot and anthracnose, resistant hybrids, S136

- diseases in Madeira Island, Portugal, S132

-El mal de Panama, Fusarium oxysporum cause, use of clones, $\mathrm{S} 123$

-Moko disease, prevalence mapping, S60

- postharvest fruit rot, control, S124

-root necrosis and associated endophytic fungi, S115

-Tetranycus and Thrips spp., control in Portugal, S118

Banana bunchy top virus, in tissue and aphids, detection, S75

Banana streak badnavirus, distribution in Venezuela, S129

Bancal, M.-O., 762

Bandla, M. D., S34

Bandyopadhyay, S., S92

Banno, S., 75

Barak, J. D., S99

Barbierri, L., 970

Bardinelli, T. R., S4, S6, S89

Bargabus, R. L., S6

Barker, B. M., 265

Barker, I., S122

Barker, R., S17

Barley

- covered smut, mating and pheromones, 210

— crown rust, resistance sources, 1064

-deoxynivalenol, light-dependent bleaching, S11

-leaf rust, partial resistance, S120

— leaf scald, molecular markers, S28

-leaf spot, physiological, oxidative stress, 145

- Rhizoctonia root rot, till and no-till fields, S74

—scald, resistance using near-isogenic lines, 710

Barley yellow dwarf virus

-aphid tranmission: gene effect on efficiency and symptoms, S48; phenotype effect, 970; specificity, binding protein, $\mathrm{S} 47$

-on native grasses, California, S50

Barnes, C. W., S6

Barnes, J. S., S6, S73, S89

Barreto, D., S65

Barrett, T. L., S6

Barrios, H., S110

Barrios, L. M., S115, S128, S129

Bartels, D., S81

Bartelt, R. J., S43

Barton, W., S89

Bartz, J. A., S99

Basinal, L. M., S62

Bastías, G., S121

Batista, L., S115

Batlle, A., S131

Batlle-Viera, A., S115

Batzer, J. C., S6

Baudoin, A., S142

Baulcombe, D. C., S129

Baum, T. J., S20, S27, S37, S85

Bauske, E. M., S76

Bayesian analysis, plant pathology use, S101

Bayles, M. B., 1323

Baysal, Ö., S115

Beach, S., 190

Bean

-root disease, soil compaction effect, S35

-root rot, Bacillus subtilis and Rhizobium seed inoculation, S24

Bean dwarf mosaic virus, on bean, resistance genetics, S75

Bean golden mosaic virus, Bemisia tabaci association, in Cuba, S119
Bean pod mottle virus

- host range in South Dakota, S138

-isolate diversity, 446

- molecular characterization of strains, S32

-on soybean, planting date effect, S29

Beattie, G. A., 1015, S97

Becherer, H. E., S10

Beck von Bodman, S., S144

Beck, H. W., S64

Becker, D., S126

Becker, J. O., S89

Becker, O., 850

Becker, T. M., S7

Beckerman, J., S7

Beckman, T. G., S68

Beebe, S., S133

Beer, S. V., 900, S42, S59, S60, S85

Beet curly top virus, in beet leafhopper, detection method, S78

Beet mosaic virus, cloning and sequence analysis, S59

Beet western yellows virus, on cabbage, relation to Cauliflower mosaic virus and Turnip mosaic virus, 816

Beet yellows virus, gene expression, S104

Begomoviruses

- diversity and management in Latin America, S127

-management, in tropics, S109

-on vegetables, cotton, and weeds, diversity in Guatemala and Honduras, S116

Bejarano, E. R., 842

Bekal, S., S7, S88

Belasque, J., Jr., S12

Bellizzi, M., S8

Bemisia tabaci

—-begomovirus on, phylogenetic analyses, S116

-biotype evolution, S96

— genome project, DNA microarrays, S116

-Tomato yellow leaf curl virus vector, in Dominican Republic, 487

— virus vector on cucurbits, reassortant, 734

Bender, C. L., S91

Benhamou, N., 424

Beno-Moualem, D., 1196

Benson, D. M., S19

Bent, A. F., S40, S53, S65, S67, S103

Bentgrass

-dollar spot, management practices, S146

- take-all, temperature and isolate effects, S146

Berger, P. H., 694

Bergstrom, G. C., 511, S17, S93

Bermudagrass

- dematiaceous hyphomycetes, inoculation technique, S66

-Pythium, overseeded golf course greens, in Alabama, S148

- spring dead spot: gene expression, S141; isolate aggressiveness at low temperature, S138

Bermúdez, D., S123

Bernal, A., S130

Bernal, F., S123

Bernard, K., S108

Bernardy, M., 87

Bernier, L., S25, S95

Bertaccini, A. F., 1038

Best, V. M., S83

Betancourt, C., S119

Bethenod, O., 1308

Bettilyon, A., S54

Beyl, C. A., S151

Bhat, R. G., S7, S68, S103

Bhatia, A., S7

Bigelow, D. M., S7

Biggs, A. R., S19, S147

Bily, A. C., S7

Biological control

- apple blue mold resistance induced by agents, 900 
—bacterial diseases, effectiveness, S108

-Botrytis cinerea in strawberry, biocontrol agent mixtures, 976

—Candida oleophila for Penicillium digitatum on grapefruit, 393

- Candida sake for pear postharvest decay, 281

-Capnodium and Coccus spp. in coffee fields, in Cuba, S122

—efficacy, adjuvant usage, S50

- environment creation, S98

-Fusarium head blight of wheat, in Ohio, S23

-Fusarium oxysporum: Fot1 element, 936; for Fusarium wilt on cucurbit, 164

-Fusarium wilt of tomato, nonpathogenic species, 1160

- genotype and pathogen strain, match up, S98

- human pathogens, foodborne, S99

—indigenous and introduced agents, S99

- microbial antagonists, pathogen self-defense, S99

-nematodes, holistic approach, S98

- Pantoea agglomerans for apple fire blight, 1202

-Penicillium oxalicum for tomato Fusarium wilt, 863

_ plant nutrition manipulation, S98

- postharvest disease caused by Colletotrichum coccodes, 33

-Pseudomonas fluorescens, in rhizosphere, population monitoring, 129

- Pseudomonas putida: on citrus soil microbial communities repetitive applications, 857; for Phytophthora parasitica in citrus, 850

-Puccinia jaceae for starthistle control, 355

- soil factors, S98

- systemic resistance induced by, host responses, S6

-tomato bacterial speck, hrpS mutants, 1284

-Trichoderma spp.: for cotton damping-off, 177; to Rhizoctonia solani, Botrytis cinerea, S121

-Trichoderma stromaticum for Crinipellis perniciosa on cacao, 1032

Bird, D., S103

Bjørnstad, Å., 710

Black, L. L., S143

Blackwell, B. A., S7

Blackwell, M., 1276

Blaha, G., S2

Blaine, M. A., S148

Blanc, S., 65, 576

Blankenheim, Z. J., S7

Blehm, E. S., S8, S35

Block, C. C., S8, S56

Blodgett, J. T., S8

Blok, V. C., 884

Blomquist, C. L., 1218

Bloomberg, J. R., S148

Blueberry

- mummy berry disease: current status in North

America, S146; infection factors, 1104

-Septoria leaf spot, defoliation and yield, A1025

Bluestem, rust, fire effect on infection, S6

Bluhm, B. H., S8

Blumeria graminis, on Hordeum vulgare and Arabidopsis, germ tube formation, S23

Boal, R. J., 1210, S88

Bockus, W. W., S42, S140

Boehm, M. J., S23, S40, S80

Boerboom, C., S45, S46

Boher, B., 336

Boland, G. J., 780, S19

Bolick, E. A., S132

Bolton, M., S8, S137

Bonacci, B. B., S67

Bonants, P. J. M., 464

Bond, J. P., S3, S71, S152

Bonde, M. R., 217, S142

Bonello, P., S8
Bonfil, D. J., 417

Boonham, N., S122

Boosalis, M. G., S8

Boozer, R., S76

Borges, O., S117

Borneman, J., 857, S82, S89

Borrás, O., S117, S133, S134

Bos, J., S102

Bostock, R. M., A1024, A1025

Botryosphaeria dothidea, on pistachio

- detection of RNA, S14

-isolate characterization in California, 519

Botrytis cinerea

- benzimidazole and dicarboximide resistance, in Spain, $\mathrm{S} 82$

-biofilm role, biocontrol, S67

- dicarboximide resistance, 75

- in grape and berry and buds, competition, S21

—on strawberry, biocontrol agent, 976

-Trichosporon pullulans vector, 1293

Botti, S., 1038

Bottner, K. D., S39

Boudon-Padieu, E., 384

Boudreau, M. A., S21

Boudreaux, J. E., S153

Bouhouche, N., S84

Bourab, K., S103

Bowden, R. L., 1152

Bowen, B. W., 1245

Bowen, K. L., S8, S12, S76, S148

Bowers, J. H., S2, S72

Bowles, M. L., S39

Boyetchko, S. M., S9

Boyhan, G. E., S44

Brading, P. A., 439

Bradley, C. A., S9

Brainard, K. A., 43, 893

Brannen, P. M., S9, S25, A1025

Brantner, J. R., S9

Brassica spp.: bacterial pathogens, reaction, S91; black rot, race-specific resistance inheritance, 1134; black rot, resistance sources and origin, 105

-B. napus: polygalacturonase inhibitors, stress and infection, S47; stem canker, new avirulence genes, 1122

Brecht, M. O., S148

Breeden, T. S., S9

Breeding

- marker-assisted, future, S106

-microarray use in programs, S106

Bremia lactucae, on lettuce, warning system, temperature and solar radiation, 631

Brenneman, T. B., S74, S102, S149, S151, S152

Brinkerhoff, L. A., 1323

Brito, J., S107

Britton, K. O., S13

Brlansky, R. H., S71

Brocherieux, C., 336

Brock, J. H., S113

Brodzik, R., 1260

Brolley, B., S18

Bronson, C. R., S80

Brook, M., S91

Brown, A. H. D., S28

Brown, D. (North Carolina), S80

Brown, D. W. (Illinois), S93

Brown, J. E., S9, S79

Brown, J. K. M. (England), 439

Brown, J. K. (Arizona), 734, S9, S38, S96, S116

Brown, L. G., S100

Brown, R. (Canada), S13

Brown, R. L. (Louisiana), 1084, S15

Brownback, L. E., S10

Browne, G. T., S10

Browning, M., S10

Bruckart, W. L., 355, S142, S143

Bruening, G., S10

Brûlé-Babel, A. L., 138
Bruton, B., S90

Buchner, R. P., S49

Bucholtz, D. B., S5

Buck, J. W., S10, S58

Buckley, P. M., S87

Bucklin-Comiskey, S., S45

Buechley, G., S75

Buell, C. R., S102

Buell, R., S77

Bull, C. T., 1356

Bulluck, L. R., III, 181, S10

Burd, J., 970

Burdon, J. J., S28

Burdsall, H. H., Jr., S56

Burgess, M. G., S10

Burke-Scoll, K., S72

Burkholderia spp.: biofilm phenotype, biocontrol role, S70; organic agriculture and communities in soil, $\mathrm{S} 16$

-B. cepacia: biofilm development, regulatory checkpoint, S98; in soil, population dynamics, S35

Burnham, K. D., S10, S11

Burns, J. K., S15

Burpee, L. L., S10, S152

Burr, T. J., S108

Buruchara, R. A., 580

Buschmann, H., 59

Bush, E. A., S11, S142

Bushnell, W. R., S11

Bustamante, M., S127

Butcher, C. J., S27

Butrón, A., S149

Buyer, J. S., S48, S69

Buzayan, J. M., S10

Byer, K., S9

Cacao

- black pod, fungicides for in Papua New Guinea, S2

-witches'-broom, mycoparasite and biocontrol, 1032

Cacopsylla pyricola, on pear, decline phytoplasma, California, 1218

Cadena Hinojosa, M. A., 688

Cadet, P., S69

Caesar-TonThat, T., S45

Café-Filho, A. C., S11, S30

Cai, G., S11

Caladium, tuber treatments, disease control, S150

Callow, J. A., 378

Callow, M. E., 378

Camacho, R., S117, S131

Camara, M. P. S., S83

Camargo, L. E., S118

Cameron, K. D., S11, S41

Camilli, K., S4

Campaña, A., S127

Campaña, M. A., S11

Campbell, H. L., 1284, S12

Campbell, R. N., 288

Campo-Arana, R., S119

Campos, Z. R., S12

Canales, H., S135

Candida spp.

-C. oleophila, biocontrol agent for Penicillium digitatum on grapefruit, 393

-C. sake, biocontrol for pear postharvest decay, 281

Candresse, T., 169, 563

Canola, white mold, phylogeography and genotype-symptom association, early and late infection, 785

Canteros, B. I., S116, S128

Cantoral, J. M., S82

Cao, Y., S33

Caolo-Tanski, J. M., S12

Capell, B., S68

Capsicum annuum 
-Amaranthus lividus effect on, microherbicide application, S58

-bacterial spot: hypersensitivity and temperature, 197; non-hypersensitive responses, 173; resistance gene on leaf, cover photo, February -root-knot nematode, resistance, $\mathrm{S} 80$

Carbone, I., 785

Carbonero, P., S114

Carbú, M., S82

Cárdenas, W., S116

Cardwell, K. F., 120

Carisse, O., 424, 769

Carkaci-Salli, N., S104

Carling, D. E., 43, 893

Carmona, E., S133

Carpenter-Boggs, L., S7

Carriquiry, A. L., S101, S102

Carris, L. M., S36, S61

Carroll, G. C., 464

Carroll, N. B., S112

Carrot

—blight, pathogen genetics, S55

-IPM status, baseline information in Wisconsin, S70

—white mold, fertilization effect, S78

Carter, E., S22, S85

Carter, L., S151

Carter, T. L., S38

Cartinhour, S., S102

Cartwright, R., S56, A1025

Caruso, F. L., S12

Caruso, F. V., S61

Carvajal, C., S134

Carvajal, O., S118, S130

Casassa-Padrón, A., S131

Castañera, P., S114

Castell, C., S12

Castellano, G., S117, S131

Castillo, M., S119, S127

Castillo, P. D., S43

Castro, A. C., S84

Catlett, N., S102

Catlin, N. J., S12

Cauliflower mosaic virus

—on Arabidopsis, resistance breakage, 190

-on Arabidopsis thaliana, resistance breakage, encoding portion, $\mathrm{S} 46$

-on cabbage, relation to Beet western yellows virus and Turnip mosaic virus, 816

Cavaletto, J. R., S30

Cavin, C., S142

Cazorla, F. M., 909

Celery, late blight, chemical control in California, S129

CENSA

-IACR-RES basis for collaboration, five-year study, S124

-international collaboration, S123

Centaurea solstitialis, rust, teliospore germination factors 355

Centeno, F., S117

Ceratocystis spp.

-C. fagacearum: on oak, transpiration reduction, S88; overland transmission, role of Clonostachys rosea, S59; sap beetle pheromones, overland transmission, S43

-C. fimbriata: host specialization, phylogenetics, S122; on trees, allozyme and DNA analysis, $\mathrm{S} 40$

Cercospora spp.

- C. beticola: cerosporin, bioassay, $\mathrm{S} 45$; on sugar beet, weather, Netherlands, S83

-C. kikuchii, vegetative compatibility groups, nitrate nonutilizing mutants, S11

-C. zeae-maydis: cercosporin biosynthesis, genes, S76; conidia, production and liberation, S44; on corn, interaction with corn borer, S5; on corn, temperature and relative humidity effect on sporulation, S64
Cereal

—bacterial pathogens, in Russian Federation, S52

—endophytic actinomycetes, harnessing, S27

Ceresini, P. C., S12, S86

Cereus tetragonus, Glomerella cingulata, resistance and abscission layer formation, 964

Ceri, H., S51

Cerkauskas, R. F., S13

Cervantes, L. A., S78

Chakraborty, N., S13

Chakraborty, S., 553, S2, S13

Chalutz, E., S9

Champaco, E. R., S32

Chandler, C. K., S55

Chang, C. J., S9, S13, S14

Chang, H.-S., S102

Chang, K. F., S85

Chang, T. H., S13

Changa, C. M., S13

Chaouch, R., S14

Chapela, I., S95

Chapman, S., S6

Charchar, M. J., d'A., 553

Charest, J., 769

Charkowski, A. O., S88

Charudattan, R., S9, S58

Chastagner, G. A., S14, S148

Chatchawankanphanich, O., 637

Chatterjee, A. K., S35, S102

Chatzivassiliou, E. K., 603

Chellemi, D. O., 1367

Chen, C., S15

Chen, H., 750, S80

Chen, J., S14

Chen, L.-F., 1315

Chen, S. Y., S48, S56

Chen, W. (California), S102

Chen, W. (Iowa), S6, S50

Chen, W. (Illinois), S140

Chen, W.-Q. (California, China), S14

Chen, X. M., S14, S41, S106

Chen, Z. (China), S110

Chen, Z.-Y. (Louisiana), 1084, S15

Chenault, K., S15

Chestnut

—blight: 10-year study, S94; pigment biosynthesis, S76

—blight hypovirulent strains, S94

—blight spatial patterns, hypovirus spread, S94

-breeding and hypovirulence, restoration, S94

-West Salem stand, demographic analysis, S94

Chew, F.-T., 654

Chinnasri, B., S15

Chiroleu, F., 336

Chitwood, D. J., S55

Cho, K. Y., S62

Choi, D., 1095

Choi, G. J., S62

Choi, J. K., 156

Choi, S. H., S46

Choi, W., S19

Chong, S. K., S152

Chou, C.-C., S87

Christ, B. J., S16, S67, S90, S147

Christopher, D., S76

Chrobak, M., S82

Chun, W., S66, S70

Chung, K. R., S15, S16

Church, G. T., S15

Churchill, A. C. L., S76

Cicadulina, geminivirus vector, distribution in insect, 65

Cicciarelli, R., S33

Cicer arietinum, Ascochyta blight, resistance inheritance, biometric analyses, 417

Cihacek, L. J., S78

Citrange, bud union disorder, graft transmissible agent, S51
Citrus

- bacterial canker, genes, S23

-bacterial diseases, systemic resistance, S31

-brown spot: ecology, S7; brown spot, phylogeography worldwide, 794

-canker: bacterial survival in lesions and inoculum dispersal, 336; copper effect, S116; detection with real-time PCR, S110; eradication of bacterium, S17; field diagnosis, S53; Florida epidemic, analysis, 361; public policy, S31

- greasy spot: $\mathrm{CaCO}_{3}$, dolomite, urea effects, S57; fluorescence microscopy, S76

— viroid variance in Cuba, S134

-Xylella fastidiosa, quantification by PCR assay, 1048

Citrus exocortis viroid, other viroids, symptoms in citron, 542

Citrus tristeza virus

- component segregation, aphid transmission, S83

-on grapefruit, coat protein and resistance, S36

-hsp 70 protein homolog, biochemical characterization, S133

-isolate characterization in India, S71

-on Mexican lime: cell deterioration, S76; other virus similarities, S36

- molecular assays, in Hawaii, S151

- multiple origin of isolates in Florida, S36

Citrus yellow mosaic virus, promoter region, S37

Ciuffetti, L. M., S51, S52, A1025

Civerolo, E. L., S10, S81

Cladosporium carpophilum, on peach, moisture and conidial dispersal, S44

Clark, A. J., 446

Clarke, B. B., S146

Clarke, J. D., S102

Clavibacter michiganense

-on corn leaves, 1015

- detection and real-time PCR, S110

-on tomato, resistance loci, 504

Claviceps africana, on sorghum

— prediction model, in Mexico, S57

-weather pattern and prevalence in Texas, 659, 1026

Clayton, K., S67

Clayton, M. K., S96

Clemente, T., A1024

Cleveland, T. E., 1084, S15

Cloud, G., S108

Clough, S., S53, S103, S106

Coakley, S. M., 667

Cobb, A. C., S105

Coble, H. D., S109, S112

Cochliobolus sativus

- on barley, cereal residue burning effect, S20

- chromosome length polymorphism, S91

Cocoa, Monilia pod rot, biocontrol with bacteria, S24

Coconut

-lethal yellowing: diagnosis in Cuba, S126; epidemic in Honduras and Central America, S127

- mollicutes, plant trypanosomatids, S119

- nematodes and bacterial diseases, resistance in Honduras, S119

- phytoplasma, in embryo tissue, S118

- tinangaja viroid, detection method, S136

Codina, J. C., 909

Coelho Netto, R. A., S60

Coffee, Syngonium podophyllum and Spathodea campanulata, in plantations, mycoherbicides, S124

Coffeen, W. C., S104

Cohen, B. A., 590

Cohen, L., 393

Cohen, S. D., S15, S112

Cohen, Y., 300

Colburn, G. C., S16

Colgrove, A. (Illinois), S88

Colgrove, A. L. (Missouri), S16 
Coli, W. M., S108

Coll, Y., S119, S131

Colletotrichum spp.: biogenetic analysis, molecular characterization, S48; on pigeonpea pods, in Puerto Rico, S114; on strawberry, histopathology, 1055; on strawberry, population genetics and etiology, 1245

-C. acutatum: on almond, temperature and wetness duration, S19; on apple, polygalacturonase, $\mathrm{S} 63$; appressoria, digital image analysis, S20; on blueberry, fungicide sensitivity, S29; on blueberry, overwintering site, S18; on blueberry, spore release in Michigan, S86; on citrus, hormones in symptomatology, S15; on highbush cranberry, infection reservoir, S143; on lupin, genetics and morphology, 986; postbloom fruit drop caused by, fungicide for, S64; on strawberry, C. gloeosporioides comparison, yield reduction, S55; on strawberry, cultivar response, S117; on strawberry, plant extract effects, S45; on strawberry, protein-transgenic strains, 743 ; on strawberry, survival and dispersal, S87 fruit drop caused by, fungicide for, S64

-C. coccodes: on potato, vegetative compatibility groups, 827; on velvetleaf, biocontrol and assay detection, S142

-C. fragariae, on strawberry, cover photo, October

-C. gloeosporioides: on apple, Glomerella cingulata comparison, isolates, S30; on avocado, fruit protection mechanisms, enzyme mediated integration, 1196; biocontrol of Russian thistle, host range, S142; on lupin, field spread, tracer, 1110; on pepper, in Virginia, S142; on Stylosanthes spp., in Brazil, 553; on Stylosanthes scabra, infection and high $\mathrm{CO}_{2}, \mathrm{~S} 13$

-C. graminicola: on corn, infected leaf cells, cover photo, July; on corn, ultrastructure of infection, mutant pathogenicity, 803; on corn, ultrastructure of infection and colonization, S57; on turf, Qo inhibitors, S61

-C. lindemuthianum: on bean, cultivar reaction, S137; on bean, nontoxic protection technology, 378; on dry beans, race 73 in Canada, S18

Collins, A. A., S16

Collins, D. J., S9, S79

Collmer, A., S102

Companioni, B., S117, S133

Compost

- safety issues and human pathogen, S21

- stability on farm, S13

- tomato resistance induced by, 424

Coniophoraceae, wood decay fungi, phylogeny, S39

Coniothyrium minitans

-parasitic on sclerotia, S105

- Sclerotinia diseases controlled by, S105

Conn, K. L., 548

Connolly, M. S., A1025

Constantelos, C., S61

Contreras, N., S117

Conway, J., 105

Conway, M., S76

Conway, W. S., S46, S63, S67

Cook, D. W. M., 1293

Cook, G., S129

Cooke, L. R., S143

Cooksey, D. A., S36, S82

Coombs, J. T., S16, S27

Copes, W. E., S148

Cordell, M., S150

Cordero, M., S117

Cordova, I., S118

Corley, J. S., S80

Corn (see also Maize)

- anthracnose, ultrastructure of infection, mutant pathogenicity, 803 —antibiotics, aflatoxin, husk coverage, and chromosomes, S149

-Aspergillus ear rot and aflatoxin, inoculation method, S53

-bacterial colonization of leaves, 1015

- Fusarium in ears, growth simulation in artificial inoculation, 534

-rust, $R p 3$ gene family, $\mathrm{S} 141$

—smut, 300 hosts in Mexico, S127

- stalk rot, leaf spot and corn borer interaction, S5

- stemborers and grain feeders on, endophytic Fusarium effect on infestation, 120

-Stewart's disease: flea beetle transmission, quantification, S55; knowledge of vector, 668; management of beetles and pathosystem, S24; risk, symposium, 668

- toxigenic fungi, host differences, S87

- viruses and phytoplasmids, distribution and control, in Cuba, S122

Cornus spp., anthracnose, population structure, 1276

-C. florida; powdery mildew: bicarbonate salt and househould soap effect, 557; fungicides in Delaware, S144; protein analysis in cultivars, S4

Coronado, M. F., S134

Correll, J. C., 232, S30, S48

Corsten, M., S135

Cortes, C., S7, S123

Costa, J. C. B., 1032

Costanzo, S., S16

Cotterill, P. J., S101

Cotton

—aflatoxin in seed, in Texas, S39

-bacterial blight: near-isogenic lines for resistance, 1323; resistance screening, S72

—boll rot, mycoflora on in Alabama, S151

-damping-off, biocontrol with Trichoderma, 177

-plant growth-promoting rhizobacteria, on transplants, S149

-Pythium, Thielaviopsis, and Rhizoctonia isolation, time of planting effect, S30

- seedling disease, crop, tillage, and fungicide effect, S151; fungicides in Georgia, S150

Cotton leaf crumple virus, new phylogenetic group, S9

Cotty, P. J., S39

Couch, B. C., S16

Cover photo

-Capsicum annuum, Xanthomonis axonopodis, resistance gene $B s 2$, February

-Colletotrichum fragariae, on strawberry, October

-Colletotrichum graminicola, on maize cells, mutant strain, July

- Guignardia mangiferae, conidia, May

-Maize fine streak virus, on sweet corn, November

-Mirafiori lettuce virus, Lettuce big-vein virus comparison, March

-Peronospora tabacina, on tobacco roots, sporulation, April

- Phytophthora capsici, on cucumber, June

- pineapple, mealybug wilt, symptoms, September

-Puccinia tritici-repentis, race 1 on wheat,

January

-Trichosporon pullulans, on Botrytis cinerea sporulation, December

-Turnip mosaic virus, on cabbage, August

Cowger, C., 617, 624, 1175, S96

Cowpea chlorotic mottle virus, methyltransferase domain, accumulation in plants, S131

Cox, C. M., S137

Cox-Foster, D., S47

Coy, A. E., S33, S87

Craddock, J. H., S94

Cram, M. M., S26
Cramer, R. A., S17, S45

Cranberry

- fairy ring: cause, S61; detection by remote sensing, S62

-Phytophthora root rot, distribution in New Jersey, S145

Crane, B. R., S11

Creamer, R., 1167, S70

Creswell, T., S1, A1026

Criconemella ornata, populations and sand particle size, S84

Crinipellis perniciosa, on cacao, mycoparasite of cacao, 1032

Crisosto, C. H., S62

Cronartium spp.

-C. quercuum, axenic growth, carbohydrates, S20

-C. ribicola: on Ribes nigrum, resistance gene $\mathrm{Cr}, \mathrm{S} 65$; variation and gene flow, $\mathrm{S} 95$; on white pine, genetic specificity in pathosystem, 278

Crop protection, nontoxic technology, zosteric acid use, 378

Crow, W. T., S107

Crowley, D., 857

Crupina vulgaris, Ramularia crupinae for control, S143

Cruz, M., S117

Cruz-Jiménez, A., S132

Cryphonectria parasitica

-hypovirus deployment, canker treatment, S94

-reproductive biology, S94

Csinos, A. S., S17, S50, S74, S150, S152

Cuadrado, A., S114

Cuasquer, J., S50

Cuba, M., S121

Cubero, J. (Florida), S17

Cubero, J. I. (Spain), 1262

Cubeta, M. A., 1189, S112

Cucumber

—damping-off, biocontrol, S48

- gray mold, inhibition by galactosyl diacylglycerol, S62

- Messenger as growth enhancement, S67

-nematode management, 1,3-D and oxamyl, S17

-Phytophthora crown rot and blight, resistance induced by Trichoderma, S41

Cucumber mosaic virus

—on cucurbits, synergy with potyvirus, 51

-resistance, germ plasm screening, S29

—on zucchini squash, cross-protection, S89

Cucurbit

-Fusarium wilt, biocontrol with Fusarium, 164

- gummy stem blight, phylogenetic analysis of Didymella bryoniae, 997

- powdery mildew: ascomata survival, S146; fungicides and resistance, S144

-Zucchini green mottle mosaic virus, genome structure and production, 156

Cucurbit leaf curl virus reassortant with related viruses, on cucurbits, 734

Cueto, J. R., S115, S126

Cui, Y., S35

Culbreath, A. K., S50, S51, S149, S151

Cummings Carlson, J. E., S94

Cuppels, D. A., 1284, S1

Curley, J., S13, S17

Curry, K. J., 1055, S153

Curtis, M. J., S104

Cuscuta japonica, invasion in Texas, S4

Cylindrocarpon spp., on beech bark, killing front, Michigan, S1

- C. destructans, DNA, extraction from soil, S68

Cymbidium mosaic virus on orchid, detection

using DNA biosensors, 654

Czosnek, H., S54, S96, S116, S127

Czymmek, K., S103 
Dactylella pseudoclavata, nematode-trapping fungus, new from China, S56

da Graça, B. M., S36

da Graça, J. V., S36

Dahir, S. E., S94

Dalbulus maidis, corn stunt spiroplasma vector, S96

Daleo, G. R., S33

Damann, K. E., 1084, S15

Damicone, J. P., S91, S149

Damsteegt, V. D., S29, S75

Danyluk, G., S46

D'Arcy, C. J., S22

da Rocha, A. B., S4, S22

Datnoff, L. E., S118, S148

Datta, S., S13

Daub, M. E., S80, S83

Dauch, A. L., S142

Daughtrey, M., S146

Daus, A., 393

Davelos, A. L., S17, S94

David, P. J., S54, S55

Davidson, J. M., S17

Davidson, L. E., S17

Davies, E., S62

Davis, A. L., S67, S70

Davis, E. L., S20, S27, S37, S85

Davis, J. M., S23

Davis, M. J., S18

Davis, R. E., S91

Davis, R. F., S17, S152

Davis, R. M., S42, S55, S70, S75

Davis, T. A., S150

Dayan, F. E., S85

Deahl, K. L., S143

Dean, R. A., 997

Dean, R. A., S19, S80

Dearborn, D., S93

de Boer, S. H., S25, S46

De Cal, A., 863

de Capdeville, G., 900

Decision theory, plant pathology applications, S101

Decker, J., S18

Deckert, G., 232

Defago, G., S49, S68, S69

de Jensen, C. E., S24, S43

de Jong, S. N., S46

Deka, D., 1260

de la Fuente, L., S3

Delaney, T. P., S102

de la Torre, C., S114

Delgado, N. J., S18

Dell, K. J., S36, S37

Della Vedova, G., S82

del Loreto Rey, M., S122

de los Ángeles González, M., S121

del Rio, L. E., S18, S137, S139

DeMarsay, A., S18, S143

Dendy, S. P., S18

Deng, F., S19

Deng, J., S19

Denny, T. P., S19, S48

Deom, C. M., 729, S4, S58, S131

Derie, M. L., S21

Dery, P. D., S48, S69

de Sá, P. B., 446

Desfeux, C., S53

Desjardins, A. E., S19, S67, S93

Deslandes, L., 1142

DeValerio, J., S58

de Vallavieille-Pope, C., 1308

de Vicente, A., 909

Dewdney, M. (Canada), 769

Dewdney, M. M. (New York), S19

de Weerdt, M., v

de Werd, H. A. E., 129

DeWolf, E. D., 232, S21
Diagnosis

- laboratory certification, Agdia, S111

_ plant pathogen in Cuba, S130

Diagnostic laboratory, accreditation, ISO 17025 , S111

Diagnostic technique, immunocapture RT-PCR and ELISA, S34

Diaporthe helianthi, on sunflower, molecular variability, 308

Díaz, I., S114

Díaz, J. A., 842

Díaz, M., S118, S123, S124, S128, S130

Diaz, N., S103

Díaz Gil, M. E., S130

Díaz-Mínguez, J. M., 237

Diaz-Perez, J. C., S149

Dibotryon morbosum, on Prunus spp., internal transcribed spacers, S15

Dicklow, M. B., S147

Dickman, J. S., S86

Dickman, M. B., S104

Dickson, D. W., S107

Didymella spp.

-D. bryoniae: bioecology, S130; on cucurbits, phylogenetic analysis, 997

-D. rabiei, on chickpea, resistance inheritance, biometric analyses, 417

Dieguez-Uribeondo, J., S19, S20

Diggle, A. J., 321, 1110

DiLeone, J. A., S74

Dillard, H. R., S105

Dill-Macky, R., S20, S24, S93

Dillwith, J. W., S88, S153

Diner, A. M., S20

Dinoor, A., 976

Discula destructiva, on dogwood

—isolate characterization, S7

-population structure, 1276

Disease forecasting, Bayesian approach, S100

Disease management, inoculum dispersal, raindrop kinetic energy, 497

Disease quantification, image analysis software, S113

Disease survey, eggplant, pepper, and tomato, in Guam, S73

Dixon, P. M., S6

Diilani, F., S30

Dobinson, K., S68, S103

Dodds, J. A., S83

Dogwood (see Cornus florida), powdery mildew

Dolezal, W. E., S111

Dolja, V. V., S104

Dollet, M., S119

Domier, L. L., S34

Domínguez Valenzuela, J. A., S120

Dong, S., S102

Dongyi, H., S41

Donohue, C. M., S7

Dopkins, D. M., S34

Dorrance, A. E., S10, S11, S20, S39

Doster, M. A., S20

Double, M. L., S94

Douches, D. S., S66

Douhan, G. W., 703

Doxtader, D. C., S138

Doyle, M. M., S116, S119, S127

Driskel, B. A., 347

Droby, S., 393, S9

Drouillard, D. L., S31

Du, P. V., S110

Du, W., S20

Duan, C.-H., S21

Duan, Y. P., S21

Ducamp, F., S3

Dufault, N. S., S21

Duffie, L. E., S21

Duffy, B., S21, S49, S98, S99

Dufresne, M., S103

Dugan, F. M., S21
Dumenyo, C. K., S36

Dungan, R., 1344

Duniway, J. M., 1337, S34

Dunker, B., S139

Dunkle, L. D., S44, S76

Dunn, R. A., S107

Dunning, F. M., S65

Dupper, G. E., 278

Duran-Vila, N., S134

du Toit, L. J., S21

Duttle, A. E., S22, S53, S77

Duveiller, E., S109

Duxbury, J. M., S62

Dwyer, P. J., S22

Dyer, A. T., S9, S22

Dyer, P. S., 703

Dyer, R., S93

Dysmicoccus spp., pineapple mealybug transmitted by, 928

Dzengeleski, S. I., S22

Eastburn, D. M., S22, S61

Eastwell, K. C., 87, S44, S52

Ebbole, D. J., 917, S7

Eberl, L., S98

Echávez-Badel, R., S114, S119

Echemendía, A. L., S119

Eckhardt, L., S22

Edmonds, J., S53, S61

Edmunds, B. A., S22

Edwards, H. H., S23

Effertz, R. J., 527

Egel, D. S., S34

Ehrenshaft, M., S83

Eibl, J. M., S64

Eicken, K., S4

Eizenga, G. C., A1025

El-Abbas, F. A., S75

Elad, Y., 976

El-Allaf, S. M., S23

El-Amrety, A. A., S23

El-Arab, H. G. D., S19

El-Deeb, S., S75

Elfving, D. C., 1363

El-Hammady, M., S75

El Khalily, M. I., S23

Elleuch, A., S30

Ellis, M. A., S23

Elm, yellows, phytoplasma group, Illinois, S39

Elmer, W. H., S98, S145

Elphinstone, J. G., S110

El-Refari, M. I., S23

El Yacoubi, B., S23

Englander, L., S81

Engle, J. S., S23

English, J., S49

Ens, W., S74

Enterobacter cloacae, on cucumber, biocontrol of damping-off, S69

Epicoccosorus nematosporus, mycoherbicide on

Eleocharis kurogwai, in rice field, S37

Epidemiology, non-parametric tests, S101

Erincik, O., S23

Errata

- vol. 92, no. 3, 2002, 1253

-vol. 92, no. 6, 2002 (suppl. S1; Abad et al), 1026

-vol. 92, no. 6, 2002, 1026

—vol. 92, no. 6, 2002, (suppl.), 1024, 1025

Erwinia spp.: on mango, chemical control, S131; on watermelon, new in Illinois, S5

-E. amylovora: on apple and pear, biocontrol with Pantoea agglomerans, 1202; pathogenicity/avirulence gene, nuclear localization signal, S42; pathogenicity island, left end characterization, S85; on pear, genetics and biosynthesis, S28; on pear, strain differentiation, S40; on pome fruits, antibiotic and resistance management, $\mathrm{S} 78$; regulation by gacA, 
extracellular polysaccharides, S35; secreted proteins of, weaponry, S59; on tobacco, hypersensitive response, harpin role, $\mathrm{S} 60$

-E. carotovora, on potato, genomic diversity, S88

-E. herbicola, leaf surface interaction, S96

-E. stewartii. on corn seed, seed treatment and seed health test, S56

Erysiphe cichoracearum, on Cucurbita moschata, chemical control, S114

Escherchia coli

- farm cycle, irrigation and fertilization, S100

- growth on plants, human health risk, S21

Eskalen, A., S24, S32

Eskandari, F., 355, S143

Esker, P. D., 668, S24

Eskridge, K. M., S3

Eslava, A. P, 237

Esparza-Mantilla, M. R., S119

Espino, A., S132

Espinosa, P., S120

Espinosa-Urgel, M., S98

Essenberg, M., 1323

Estes, B., S102

Estévez, A., S117

Estrada, G., S120

Estrada Vilardell, G., S126

Eucalyptus, leaf disease survey, in Venezuela, S128

Eun, A. J.-C., 654

Eutypa lata, on grape, biopesticide, S89

Evans, C. K., S24

Evans, T. A., S74

Everts, K. L., S91

Extension, core competency training in Kansas, S111

Faba bean necrotic yellows virus resistance and cultural practice, S69

Fagus grandifolia bark epidemic, Michigan, S1

Fakhfakh, H., 563

Fakhfakh, H., S30

Falconi, C. E., S24

Fargo, D. C., S16, S24

Faria, J. C., S127

Farman, M. L., 245, 1253, 1227, 1236

Farnham, M. W., 997

Faro, C., S33

Farrar, J. J., S70

Faure, B., S133

Fazzolari, T., S5

Feau, N., S25

Feichtinger, G., S49

Fekih-Hassen, I., S30

Feldstein, P. A., S10

Feliciano, A. J., S32

Felts, D. G., S60

Feng, D. X., 1142

Feng, Q., A1025

Fengler, K., S103

Fenn, P., S150

Fenton, J. G., S3

Ferguson, L. M., S1, S25

Fermin, G., S120

Fernandes, C. D., 553

Fernández, A., S126

Fernández, E., S120

Fernandez, G. E., S1, S25

Fernández, J., S122

Fernández, N., S117

Fernández-Acero, F. J., S82

Fernandez-Pavia, S. P., S25

Fernando, W. G. D., S15, S40, S90

Ferrandino, F., 361

Ferro, C. R., S36

Ferro, J. A., S12

Ferwerda-Licha, M., S25

Fery, R. L., S80

Fessehaie, A., S25
Ficke, A., 671

Fig, fungal fruit decay, buried drip irrigation, S20

Filion, M., S143

Filippi, C., S7

Fioritto, R. J., S10

Fir, root disease, Pacific Northwest, S14

Fischer, E., 976

Fist, A. J., S101

Fitopatologia, history for 35 years, S121

Fitzmaurice, W., S104

Fjellstrom, R., A1024

Flaherty, J. E., S8, S25, S37

Fleer, J. M., S26

Fletcher, J., S90

Fletcher, W., S89

Flores G., H., S120

Flowers, J. L., S26

Fogg, M. L., S40, S143, S144

Fonseca, A., S121

Fonseca, D., S121, S126, S132, S136

Fonseca, Y., S117, S131

Font, C., S121

Food Quality Protection Act, consumer effect, S112

Foreman, G. L., S26, S138

Forest

-clearing and fire exclusion, microbe effect, S95

- ecosystems, population structure, S95

- exotic pathogens, ecosystem prediction, S15

-microbes, environment, and host variation, S95

Förster, H., S2, S19, S20, S26

Forster, R. L., S9

Fortnum, B. A., S61

Foster, A., S103

Fouly, H. M., S26

Foundling, J., S135

Fraedrich, S. W., S26

Franchino, B., 504

Francis, D. M., 504, S10

Francl, L. J., 38, 527, S3, S101

Franco, C. M. M., S16, S27

Frankiniella fusca, on peanut, feeding preference, S51

Franklin, L., S13

Frankliniella spp.

-F. fusca: on tobacco, Pantoea ananatis association, S149; Tomato spotted wilt virus vector replication in alimentary canal, 729

-F. occidentalis: Tomato spotted wilt virus replication in, S4; Tomato spotted wilt virus vector, replication in alimentary canal, 729

Franquinho Aguiar, A. M., S132

Frapolli, M., S68

Fraser, K., S62

Fravel, D. R., 1160

Frederick, R. D., 217, S66, S75

Freeman, S., 164, 743

Freeman, T., 694

French, E. R., S121

French, R., S104

French-Monar, R. D., S27

Frías-Treviño, G. A., S123

Friedmann, M., S127

Friel, C. J., S27

Friesen, T. L., 38

Froissart, R., 576

Fry, J. D., S38, S75, S138

Fry, W. E., 688, S32, S77, S145

Fuentes, A., S119

Fujii, T. M., S27

Fujimura, M., 75

Fujishige, N. A., S27

Fukui, R., S27

Fulbright, D. W., S94

Fumigation, methyl bromide, in-line injected materials as alternative, S152

Fungicides, general (see also Fungicides, specific)

-apple sooty blotch and flyspeck complex, sensitivity, S6

- cacao black pod, in Papua New Guinea, S2

$-\mathrm{EC}_{50}$ values, spiral gradient dilution method, S26

-horseradish root discoloration, S5

- IR-4, registration update, S80

- ornamental species, rooting effect, S76

-quinones, antifungal activity, naturally occurring, S85

- tree fruit crops, alternate row-spraying potential, S2

-triazole, Ceratocystis fimbriata and Botryosphaeria rhodina sensitivity, S87

- Tween 20 and cutinase, synergistic mixture, fungi inhibited by, S63

Fungicides, specific (see also Fungicides, general)

- acibenzolar-s-methyl, bacterial diseases, S108

- ammonium molybdate, pear postharvest decay control, 281

-azoxystrobin, gummy stem blight resistance, Georgia, S79

-BAS 516 F, broad-spectrum, fruits, vegetables, and trees, S89

- copper sulfate, mango resistance, Pseudomonas syringae, 909

-dicarboximide, Botrytis cinerea resistant to, 75

- Gavel and Zoxium, vegetable oomycete diseases, S77

-nicobifen: characteristics and distribution properties, S79; field crop, vegetable, turfgrass control, S6; new fungicide family, S4; use in specialty crops, $\mathrm{S} 4$

-thiabendazole, Fusarium sambucinum resistant to, on potato, 917

— trifloxystrobin, on citrus, S152

Funnell, D. L., S27

Fuqua, C., S97

Fusarium spp.: on corn ears, growth simulation, mathematical, 534; fumonisin and trichothecene, PCR detection, S8; on horseradish, fungicides and biocontrol agents, S5; isolates from crop plants and seeds, S115; on Orobanche aegyptiaca, transformation and enhancement virulence, 590; species and crop hosts in Cuba, S126; on tomato, biocontrol and environment, 1160; Trichoderma spp. for control, genetics and detection with RAPD, S118; on wheat, deoxynivalenol effect, chitinase genes in Trichoderma, S49; on wheat, head blight and crown rot in Australia, S2; on wheat and barley, scab, puroindoline proteins, S28

-F. avenaceum, on lisianthus, phylogenetic analysis, $\mathrm{S} 145$

-F. graminearum: mycotoxin, secondary metabolite, S7; on spring grains, fungicides for, S139; on wheat, cereal residue burning effect, $\mathrm{S} 20$; on wheat, REMI mutagenesis, S81; on wheat, resistance and inoculation methods, $\mathrm{S} 23$; on wheat, virulence genes, S31; on wheat, in eastern China, population analysis, 1315

-F. moniliforme, on smooth cordgrass, black leaf spot, S69

$-F$. oxysporum: on banana and plantain, vegetative compatibility groups, S115; on banana, Falso Mal de Panama, preliminary study in Canary Islands, S123; on banana, phytotoxic effect, S117; on bean, detection in plants, DNA-based procedure, 237; biocontrol mechanisms, transposition of Fot1 element, 936; on Cicer arietinum, molecular characterization in Mexico, S130; on cotton, California and Australia isolates, S42; on cucurbits, nonpathogenic mutants for control, 164; mortality, heat treatment effect, 956; necrosis-inducing extracellular protein, gene replacement, transformation, 833; Panama disease in plantations, in Canary Island, S134; on tomato, biocontrol, inoculum evaluation, 863; on tomato, compost-mediated induced resistance, 424 
-F. sambucinum: on potato, salt treatment, $\mathrm{S} 22$; thiabendazole resistance, synthetic peptides, 917

-F. solani: on dry bean, crop sequence and rootrot severity, S43; on soybean, hairy root response, $\mathrm{S} 47$; on soybean, modified oscillation medium, S149; on soybean, molecular variability, S47; substrate utilization patterns in $F$. sp., S71

-F. verticillioides: on corn, endophytic effect on stemborers and grain feeders 120; on corn, seedling pathogenicity factor, S29

Fyffe, A. E., S79

Gaba, V., 51

Gabriel, D. W., S3, S23, S53, S83

Gadoury, D. M., 671, 1068, S41

Gaeumannomyces graminis

—on bentgrass, assay, S80

- phylogeny, sequence insertions, S26

- on wheat, inhibition by Brassica mulch, S9

Gago, S., S132

Galbraith, D., S106

Gale, L. R., 1315

Gallegos, P., S39

Gal-On, A., 51

Gamba Fuica, F., S121

Gan, J., 1344

Gannaway, J. R., S72

Gao, B., S27, S37

Garay-Serrano, E., S25

Garbelotto, M., S17, S95

García Herdugo, G., S117

García, A., S127

García, D., S117

García, L., S122

Garcia, P., S121

Garcia-Pedrajas, M. D., S27

García-Sánchez, M. A., 237

Gardner, D. R., S70

Garger, S., S104

Garrett, K. A., 1152, S18, S58, S109

Garrido, M. J., S129

Garrison, S. A., S144

Garzon, C. D., S28

Gaska, J., S45, S46

Gassmann, W., 456, S90

Gatch, R., S35

Gatineau, F., 384

Gaush, P., 721, S72, S110

Gbur, Jr., E. B., S71

Geider, K., S28, S40

Geiser, D. M., 232, S28, S144, S145

Gelernter, W. D., S52

Geminiviruses, on bean, PCR and DNA hybridization methods for detection, S131

Genes, human vs. plant pathogens, number, S103

Genger, R. K., S28

Genomics, comparison in fungal plant pathogens, S102

Genowati, I., S143

Geranium, phyllosphere, biofilm of biocontrol agent, S74

Gerber, J. F., S28

Gergerich, R. C., 646, S28

Gerhardt, S. A., 210, S28

German, T. L., S86

German-Retana, S., 169

Ghabrial, S. A., 446, S32

Ghanim, M., S96, S116

Ghiasvand Ghiasi, K., 59

Gianessi, L. P., S112

Gibberella

- G. circinata, on pine, mating population, S27

- G. moniliformis, fumonisin biosynthetic genes, S67

-G. zeae: ascospore discharge, mechanism, S43; biological diversity, toxins, Nepal, S19; perithecia, weather variables, S21; sexual repro- duction, molecular determinants, S93; spore dispersal and regional epidemiology, S93

Gibson, D. M., S76, S84

Gidekel, M., S121

Gielser, L. G., S29, S141

Gigliotti, E. A., S118, S130

Gilbert, G., S95

Gilbertson, R. L., 487, S55, S75, S78

Gilchrist, D. G., S104, A1025

Gildow, F. E., S29, S47

Gillaspie, Jr., A. G., S29

Gillett, J. M., S29

Ginzburg, C., 956

Gitaitis, R. D., 893, S84, S149

Glazebrook, J., S102

Gleason, M. L., S6, S22, S29, S45, S87

Glenn, A. E., S29

Glenn, D. L., S30

Glienke de Blanco, C., 464

Gliricidia sepium, disease of, new in Honduras, $\mathrm{S} 127$

Gloeophyllum trabeum, quinone reduction system, S145

Glomerella cingulata, on apple cactus, resistance response and abscission layer, 964

Glycine wightii, control in citrus orchards, S120

Goates, B. J., S30

Goheen, E. M., S30, S54

Gold, S. E., 785, S27

Goldhamer, D. A., S20

Goldman, G. H., 1048

Goldschmidt, E. E., 393

Golino, D. A., S3, S71

Gomaa, N. G., S30

Gomez, L., S30

Gomez, O., S126

Gómez Kosky, R., S125

Gonsalves, C. V., S122

Gonsalves, D., S120, S122

González, A., S119, S131

González, C. (Venezuela), S131

Gonzalez, C. F. (Texas), 917

González, D., S115

González, E., S30, S123

González, G., S117, S119, S123

González, J. L., S134

González, L., S122

González, M. E., S122

González, M. S., S128, S135

González, V., S126

González, Y., S121, S123

González Guardiola, Y., S126

González Ochoa, F., S129

González Ramos, E. M., S132

Goodwin, P., S2

Goodwin, S. B., S2, S30, S68, S81

Gordon, D. T., 1167

Gordon, T. R., S27

Gorsane, F., S30

Goswami, R. S., S31

Gottwald, T. R., 361, S31

Götz, N., S4

Gouin, C. T., S49

Gounou, S., 120

Gourbière, F., S69

Graef, G., S29

Graham, J. H., 361, S16, S17, S31

Graham, M. Y., S31

Graham, P. H., S24

Graham, T. L., S23, S31, S45

Graminella nigrifrons, Maize fine streak virus vector, 1167

Granatstein, D. M., 1363

Granier, M., 65

Grant, J. A., S10

Grape

-berry rot, fungicides and rot severity, resveratol, $\mathrm{S} 77$

-black rot: berry age and incubation period factor, 1068; epidemiology and management, symposium, 676

-Botrytis, early infection, S91

- closterovirus, characterization, S71

-oil application and photosynthesis, factors, S142

-Phomopsis cane and leaf spot, disease predictive model, S23

-Pierce's disease: distribution in North Carolina, S35; pattern in California, S81; PCR for on-site diagnosis, 721

- powdery mildew: ontogenic resistane and disease management, symposium, 671; quinoxyfen for control, in USA and Europe, S58

-replant disorder, specificity, S10

- viruses, survey in Oregon and Washington, S52

Grapefruit, Penicillium digitataum resistance induced by yeast, 393

Grapevine leafroll associated virus, molecular detection, S3

Grau, C. R., S31, S42, S43, S44, S45, S46, S50, S67, S78, S137, S138, S139, S140

Graves, W. R., S54

Gray, S. M., 970

Green, E. A., S58

Green, T. A., S109

Greene, S. E., S31

Greer, N. W., S149

Gregory, N. F., S144, S151

Gregos, G., S72

Gregos, J., S13

Gressel, J., 590

Greve, L. C., S70

Griffiths, H. M., S39, A1024

Grimme, E., S31

Grisham, M. P., S32

Gritsenko, M. A., 265

Grondin, M., 65

Groom, T., S65

Gross, D. C., S49

Gross, P. L., S18, S137, S139

Groth, J. V., 755, S6

Grove, G. G., 1210, S21

Groves, C. L., S32

Groves, C. T., 1189

Grube, R. C., S32

Gruber, M., S47

Grünwald, N. J., 688, S25, S32

Grybauskas, A. P., S5

Gu, H., 446, S32

Gu, Y.-H., 1363, 1301, S53

Guan, J., S32, S58, S138, S140

Guanipa, N., S117, S131

Gubler, W. D., S24, S32, S36, S37, S100

Gudmestad, N. C., S137

Guenzi, A. C., S140, S141

Guerber, J. C., S48

Guetsky, R., 976

Guevara, M. G., S33

Guignardia spp.

-G. citricarpa, endophyte on woody plants, 464

- G. mangiferae, conidia, cover photo, May

Guilleroux, M., S103

Guinardia bidwellii, on grape, berry age and incubation period, 1068

Guixiu, H., S41

Gulya, T. J., 694

Gunawardena, U., S102

Gundersen-Rindal, D. E., 1038

Gundersheim, N. A., S35

Guo, B. Z., S33, S149

Gutiérrez, A., S121

Gutiérrez, C., S121

Guzman, P., 487

Gwinn, K. D., S31

Haber, S., S74

Hacker, J. K., S72 
Hadidi, A., S75

Hagan, A. K., S12, S33

Halgren, A. B., S82

Hall, J. A., 1323

Hall, T. W., S33

Halverson, L. J., S97

Ham, J. H., S33, S67

Hamada, W., S102

Hameed, K. M., S34

Hamel, C., S143

Hamelin, R. C., S25, S95

Hamer, J. E., S42

Hamer, J. L., S148

Hames, A., S135

Hamilton, S. L., S31

Hammer, W., S21

Hammerschmidt, R., S4, S22, S66

Hammond, R. W., S59, S105

Hammond, T. M., S33

Han, S. S., S46

Handoo, Z. A., S26

Haney, C. H., S77

Hanke, W., S4, S79

Hanna, J. W., S95

Hanna, L., S71

Hanna, W. W., S87

Hansen, E. M., 112, S17, S30, S33, S47, S54, S63, S95

Hansen, J. M., S78

Hanson, L. E., S12, S33

Hanson, P. M., S109

Hanson, S. F., S33

Hao, J. J., S34

Hapiak, M., S46

Harakava, R., S83

Harb, A. M., S34

Harbaugh, B. K., S145

Harikrishnan, R., S34

Harmon, P. F., S34

Harness, A. M., S34

Harreus, A., S4

Harrington, T. C., S6, S40, S122

Harrison, B., S34

Harrison, H. F., S150

Harrison, K., S65

Harrison, N. A., S118, S119

Harrison, S. A., S69

Harrison, U. J., S35

Hart, A., S77

Hartman, G., S36, S47, S139

Hartman, J. R., S26

Hartung, J. S., S14, S37, S49

Harveson, R. M., S8, S35

Hasegawa, H., S35

Hashim, J. M., S81

Hashimoto, C., 75

Hashmi, R. Y., S149

Hataya, T., 542

Haudenshield, J. S., S35

Hausbeck, M. K., 681, S112, S139

Hawes, M., S18

Hay, F. S., S35, S65, S101

Haynes, K. G., S16, S90, S147

Hazanovsky, M., 827

He, C. Y., S35

He, M. X., S56

He, S. Y., S92

Hebbar, P. K., 1032, S2, S72

Heckman, J., S146

Hegedus, D., S47

Heidel, G., S79

Heidenreich, M. C., S33

Heinz, R. D., 456, S59

Heist, E. P., 400, S35

Helicotylenchus spp., on bermudagrass, cultivars, S152

Helland, S. J., S29

Henny, R. J., S60

Henríquez, M. A., 580, S50
Her, R. J., S61

Hernández, A., S122, S131, S136

Hernández, C., S131

Hernández, J. M., S123, S134

Hernández, K., S117

Hernández, L., S120

Hernández, M. R., S115, S134

Hernández, R., S114, S123

Hernández, S., S123

Hernández Díaz, C., S119

Hernández-Hernández, M. R., S123

Hernandez-Martinez, R., S36

Hernick, C. A., 1315

Herrera Isla, L., S124

Herrera, A., S128

Herron, C. M., S36

Hert, A. P., S36

Hess, N., S22, S85

Heterobasidion annosum, on Christmas tree, mortality in Pacific Northwest, S14

Heterodera glycines

-cDNA library, amplified RNA approach, S85

—hatching signal, $\mathrm{pH}, 456$

-putative parasitism genes, in esophageal glands, S27

-on soybean: AFLP markers and virulence, S16; Fusarium solani population level, nearisogenic lines, S38; isolate variation, S88; polymorphism, mutant inbred line reactions, S7

Heterodera schachtii, soil suppressiveness, detection by fingerprinting, S89

Hewlett, T. E., S21, S28

Hibiscus, tobamovirus, characterization, A1024

Hickey, W., S68

Hidalgo, E. I., S115, S128, S129

Hientze, C. A., S4

Higgins, R., S8

Hilf, M. E., S36

Hill, A. L., S12

Hill, C. B., S36

Hill, J. H., 478, S140

Hill, J. P., S12

Hill, W., S146

Hinsa, S., S98

Hinton, D. M., A1024

Hippolyte, I., 65

Hirano, S. S., S96

Hiromoto, B., S70

Hirsch, A. M., S27

Hirsch, J, 1142

Hirsutella rhossiliensis, nematode parasitized by, $\mathrm{pH}$ effect, $\mathrm{S} 48$

Ho, H. H., S89

Hodge, K. T., S77

Hoefnagels, M. H., S138

Hoff, J. A., S36

Hoffman, L. E., 676, 1068, S36, S37

Hogenhout, S. A., 1167, S5, S14, S90, S96

Hogg, D. B., S137

Hoitink, H. A. J., S13, S41

Hokanson, S., S49

Holbrook, C. C., S33

Hollingsworth, C. S., S108

Holmes, G. J., S37, S112, S124

Honda, Y., S38

Hong, C., 610, S11, S142, S143

Hong, Y. K., S37, S45

Hop stunt viroid, on citron, with other viroids, 542

Hopkins, A., S148

Hopkins, D. L., S86

Hoplolaimus galecatus, on bentgrass, cultural practice relation, $\mathrm{S} 75$

Horken, K. M., S104

Horn, B. W., S1

Horning, J. L., S138

Horowitz, S., 743

Horseradish, root discoloration, fungicides and biocontrol agents, S5

Horten, T. B., S74

Horvath, B. J., S37

Hosta, crown rot, mulch type and placement, S22

Hou, H. S., S67

Hou, Z., S81

Houghton, W., 1167

Howard, R. J., S85

Howell, C. R., 177

Hu, J. S., 928, S76, S151

$\mathrm{Hu}, \mathrm{S} ., \mathrm{S} 19$

Huang, G., S37

Huang, J.-H., S48

Huang, J.-S., S87

Huang, L., 654

Huang, Q., S37

Huang, Y., S21

Huber, D. M., S80, S98

Huber, L., 1308

Hudak, J., S14

Hudelson, B. D., S26

Hudler, G. W., A1024

Hughes, G., S100, S101

Hughes, M. G., S62

Huh, G.-H., S37

Huitema, E., S102

Hulbert, S., S141

Human health

- foodborne pathogens on produce, S99

- pathogens on plant-derived foods, S99

Human pathogens, foodborne, chemical control, S99

Hummel, R. L., S148

Hummer, K. E., S65

Humulus lupulus, disease surveys in Argentina, S65

Hunger, R. M., 347, S38

Hunt, T. (Nebraska), S29

Hunt, T. D. (Alabama), S74

Hunter, D., S2

Hunter, P. J., 816

Hussey, R. S., S20, S27, S37, S85

Hwang, S. F., S85

Hypersensitivity

- pepper to bacterial spot pathogen, 273

-Xanthomonas axonopodis on pepper, temperature effect, 197

Hypervirulence, transgenically enhanced expression, indole-3-acetic acid, 590

Hypovirulence, Sclerotinia sclerotiorum and $S$. minor, dsRNA transmission, 780

Ibañez, A., 794

Ibn-I-Hassan, O., S124

Ichiishi, A., 75

Identification, plant pests, interpretation, S100

Idris, A. M., 734, S9, S38, S116

Ieki, H., 542

Igarza, Y., S123

Iglesias, A., S118, S120, S124, S130

Ignatov, A. N., S52

Igwegbe, E. C. K., S9

Ikeda, S. S., 780

Impatiens necrotic spot virus, on peanut and sunflower, susceptibility, S50

Ingham, R. E., S77

Inglis, D. A., S63

Insects, lepidopterous stemborers and coleopteran grain feeders, on corn, Fusarium effect, 120

Integrated pest management

- consumer communication, S108

—eco-labeling, S109

-labeling, federal perspective, S109

-Massachusetts certification, S108

-retailer marketing, S109

Internet (see also website), fungal pathogen data-

base, model, letter to editor, 232

Iriarte, F. B., S38, S138 
Irrigation, Phytophthora spp. in water, pear fruit infection, 1210

Isaka, M., 542

Isakeit, T., 694, S57

Isgrigg J., III, S38

Ishihara, H., S65

Islam, S. Z., S5, S38

ISO certification, accredited labs, S111

Ito, T., 542

Iwanami, T., 542

Jabaji-Hare, S. H., S142, S143, S144

Jackson, E. W., S150

Jackson, K. E., S55

Jackson, L. E., S6, S108

Jackson, N., S10

Jackson, T. A., S38

Jacob, N., 384

Jacobs, J. L., S38

Jacobs, K. A., S39

Jacobsen, B. J., S6, S31, S44, S106

Jada, N., S93

Jaime-Garcia, R., S39

James, R. V., S105

James, S., S124

Jandoubi, L., S30

Janisiewicz, W. J., S39, S46

Jankaew, K. S., S27

Jantasuriyarat, C., S39

Jaquez, J., 487

Jara, C., S50

Jardine, D. J., S111

Jarosz, A. M., S19, S94

Jasalavich, C. A., S39

Jeffers, S. N., S21

Jellison, J., S39, S73, S145

Jensen, A., 710

Jensen-Tracy, S., A1024

Jesperson, G., 87

Jetiyanon, K., S39

Ji, P., 1284

Jia, H., S39

Jia, Y., A1024, A1025

Jiang, T., S82

Jiménez, M. I., S116, S124

Jin, Y., 1064

Jo, Y., S40

Joardar, V., S92

Jock, S., S40

Joel, D. M., 1262

Johnson, D. (Minnesota), S17

Johnson, D. A. (Washington), S41, S66

Johnson, J. A., S40

Johnson, J. C., S34

Johnson, K. B., 1202

Johnson, R. D., S62

Johnson, R. R., 273

Johnson, S. V., S54

Johnsongrass mosaic virus, new virus relation, S74

Johnston, S. A., S40, S143, S144

Jomantiene, R., S91

Jones, A. M., S103

Jones, C., 456

Jones, D., S79

Jones, J. B., 273, 1284, S6, S27, S36, S57, S60, S108

Jones, J. (Louisiana), S22, S85

Jones, J. E. (U. K.), 816

Jones, P., S115, S118

Jones, R. W., 33, S143, A1024

Jones, S. S., S137

Joppa, L. R., S78

Jordahl, J. G., 527, S139

Jordan, D. L., S64

Jordan, R. L., 694

Jung, G., S13, S17, S72

Jurke, C. J., S40

Jurkowski, G., S40, S103

Juzwik, J., S43, S59, S88
Kabelka, E., 504

Kabir, Z., S40

Kado, C. I., S84

Kahn, B. A., S149

Kamoun, S., S102

Kanaan-Atallah, Z., S41

Kanaskie, A., S30, S54

Kanetis, L., S26

Kang, L., S138

Kang, S., 232, S41, S68, S103, S144

Kang, Y., S48

Kano, T., 542

Karasev, A. V., S105

Karasev, A., 1260

Karkashian, J. P., S125, S127

Karr, A., S49

Katan, J., 956

Katis, N. I., 603

Katzir, N., 1262

Keever, Z. T., S124

Keinath, A. P., 997, S150

Kelemu, S., S41

Keller, K. E., S82

Keller, N. P., S33, S73, S81, S91

Kelly, A. T., S150

Kelly, S. P., S108

Kema, G. H. J., 439, S30

Kemerait, R. C., S150

Kemmitt, G., S22, S53, S61, S77

Kennelly, M. M., S41

Kentucky bluegrass, summer patch, liming and nitrogen effect, S146

Kepka, G., S111

Kerkoud, M., 1077

Kers, J. A., S41

Khan, A. (California), S32

Khan, A. J. (Oman), 1038

Khan, J., S41

Khan, M., S41

Khan, V. A., S9, S79

Khang, C. H., S41

Khanna, A., S106

Kiewnick, S., S41

Killigrew, B. X., S42

Kim, B. V., S105

Kim, C. H., S46

Kim, H. (South Carolina), S39

Kim, H. T. (Korea), S62

Kim, J.-C., S62

Kim, J. F., S85

Kim, K.-H., 964

Kim, K. S., 646

Kim, K. W., 1095

Kim, M.-S., S39, S95

Kim, S. (Florida), S64

Kim, S. C. (Korea), S37, S45

Kim, S. G. (Korea), 1095

Kim, S. H. (Pennsylvania), S42, S58, S144

Kim, W. S. (New York), S42, S60

Kim, W.-S. (Germany), S28

Kim, Y. (Indiana), S42

Kim, Y. C. (Korea), S51

Kim, Y. H. (Korea), 964

Kim, Y. K. (Kansas), S42

King, G. J., 1134

King, P. C., S6, S60

Kingsley, M. T., S110

Kinkel, L. L., S17

Kinloch, B. B., Jr., 278

Kinney, D., S102

Kinziger, A. E., S42, S43

Kirk, W. W., S22, S66

Kirkpatrick, B. C., 1218, S70

Kirkpatrick, S. C., S27

Kistler, H. C., 1315, S31, S81

Kline, W. L., S40, S144

Kloepper, J. W., 1329, S39, S149

Klopfenstein, N. B., S36, S95

Kluepfel, D. A., S61
Knapp, E., S46

Knoedler, J., S146

Knogge, W., S28

Kobayashi, D. Y., S91

Kobiler, I., 1196

Koehle, H., S79

Koehler, K. J., S6

Koeller, W., S61

Kogel, K.-H., 59

Kohn, L. M., 785, S16, S42

Koike, S. T., S40

Köller, W. K., S63

Kong, P., 610, S143

Koprowski, H., 1260, S105

Kornahk, T. E., S23

Kornoely, J. P., S61

Kosted, P. J., 210, S43

Kotcon, J. B., S72, S77

Kousik, C. S., 197, 273

Koutsoudis, M., S57, S97, S144

Kowieski, T. M., S81

Krasnoff, S., S76

Kraus, G. A., 456

Kraus, J., S65

Krause-Sakate, R., 563

Kravchenko, A. N., S22, S37

Krenzer, E. G., S38

Krishna, V., 1334

Kroken, S., S102

Kromroy, K. W., S43, S88

Krueger, D. E., S11

Krueger, W. H., S49

Kucharek, T. A., S148, S150

Kuehnle, A. R., S27

Kühn, M. L., 1122

Kuldau, G. A., 232, S93

Kulemeka, B. P., S34

Kuninaga, S., 43, 893

Kunkel, B. N., S92

Kurdyla, T., S4

Kurle, J. E., S43

Kurtzweil, N. C., S31, S43, S45, S46, S78, S139, S140

Kuykendall, L. D., S43

Kwak, D. Y., S45

Kwon, C. (Michigan), S43

Kwon, C. Y. (North Dakota), 38

Kyhl, J. F., S43

Labavitch, J., S70

Lacy, G. H., S143

Lamari, L., 138, S113

Lamb, E. M., S71

Lambert, K. N., S7

Laminaria digitata, beta 1-3 glucan, resistance induced by, S108

Lamka, G. L., S111

Lamondia, J. A., S107

Lamour, K. H., 681, S139

Lamppa, R. S., S18, S137, S139

Lamprecht, S., S52

Lan, Z., S44

Landa, B. B., 129, S61

Lane, G. A., S62

Lane, L. C., S44, S141

Langham, M. A. C., S138

Langston, D. B., Jr., S44, S79

Lannou, C., 762

La O, M., S125, S126, S128, S132

Lapaire, C. L., S44

Lapidot, M., S127

Larena, I., 863

Larkin, R. P., 1160, S44, S80

Larrinaga, L., S134

Larrue, J., 384

Larsen, R. C., S44

Larson, B. J., S44

Lartey, R. T., S45

Larue, C. T., S45 
Latin, R., S10, S34

Lauer, J. G., S140

Laux, P., S115

Lawrence, C. B., S17, S45

Lawrence, G. W., S150, S151

Lazarovits, G., 255, 548, S1

Lazarowitz, S. G., S102

Le Cam, B., 314

Le Gall, O., 169, 563

Leach, J. E., S46, S65, S112

Leal, P., S121

Leandro, L. F. S., S45, S87

Leconte, M., 1308

Lee, B. C., S37, S45

Lee, B.-N., S102

Lee, C. W., S78

Lee, D. C., S45

Lee, D. R., S122

Lee, F. N., A1025

Lee, H. K., S150

Lee, I. M., S39, S45, S52, S91

Lee, K. W., S45

Lee, M. E., S45, S46, S139

Lee, M. H., A1024

Lee, R. D., S33

Lee, R. F., S133

Lee, S. W., S46

Lee, T., S93

Lee, Y. M., S10

Lee, Y.-H., 232

Lee, Y-W., 232

Lefevre, C., S7

Legard, D. E., 1245, S50, S55

Legg, J. P., S109

Legumes, new fungi from Niña Bonita, S120

Lehman, J. S., 1104, S146

Leibrecht, A., S65

Leininger, T. D., S13, S87

Leisner, S. M., 190, S46

Leite, R. P., Jr., S31

Lemos, E. G. M., S12, S86

Lennox, C. L., S46

León, O., S125, S126

Leong, S., S17

Leptographium spp., on loblolly pine, rootfeeding insects, S22

Leptosphaeria maculans, on oilseed rape, new avirulence genes, 1122

Lerner, J. M., S144

Lett, J.-M., 65

Letter to the editor

-Alfalfa mosaic virus, on soybean, chimeric rabies peptide, reexamination, letter to editor, 1260

-Internet-based fungal pathogen database, model, 232

- potato late blight, Mexican national program, 688

-Tilletia indica, allee effect and invasive potential, 1152

Lettuce

—aster yellows phytoplasma, strains, S90

- downy mildew, warning system, temperature and solar radiation, 631

—Verticillium dahliae, resistance analysis, S7

Lettuce big-vein virus, Mirafiori lettuce virus comparison

— cover photo, March

-transmission and etiology, 288

Lettuce mosaic virus

—resistance, recombinant virus for testing, 169

-resistance-breaking isolate, characterization, 563

Leverentz, B., S46, S99

Levesque, C. A., S25, S46, S64

Levy, L., S53

Levy, M., S81

Lewandowski, D. J., S46, A1024

Lewellen, R. T., S87

Lewers, K., S49
Lewis, P. I., S112

Leyva-López, N. E., S125

Lherminier, J., 384

Li, C., S47

Li, J. X., S139, S141

Li, L., S47, S80

Li, R., S47

Li, S. (Illinois), S47, S139

Li, S. D. (Beijing), S56

Li, S. F.-Y. (Singapore), 654

Li, W., S69

Li, Y., S36, S46

Lichtenzveig, J., 417

Lightner, G., S19

Lima, R. D., S107

Lindbo, J. A., S104

Linde, C. C., 946

Linderman, R. G., S47, S63

Lindgren, P. B., S85

Lindhout, P., S120

Lindow, S. E., S96, S97

Ling, H., S3

Lippok, B., S103

Lipps, P. E., S20, S21, S23

Lissorhoptrus brevisrostris, extracts from, inhibitors, S119

Little cherry virus, Canadian isolate, nucleotide

sequence and genome organization, 87

Liu, B., S48

Liu, H. (Georgia), S19, S48

Liu, H.-Y. (California), S87

Liu, S., S48

Liu, X. Z., S56

Llauger, R., S126

Llorente, I., 99

Lo, C. T., S48

Locke, J. C., S48

Lockhart, B. E., S129

Lohrke, S. M., S48, S69

Lolium perenne, gray leaf spot

-isolate comparison and hosts, 245, 1253

-resistance mapping, S17

Longidorus sp., on loblolly pine, host range and distribution, S26

Loper, J. E., 1202

López, D., S120

López, M. O., S120

López, R., S125, S126

López, Y., S133

López Manes, D., S126

López-N., J. E., S123

Lorang, J. M., S104

Lorbeer, J. W., S35, S82

Lorenz, G., S4, S79

Lorenzo, J. C., S120

Loria, R., S11, S16, S41, S84

Lot, H., 288, 563

Louws, F. J., S1, S16, S24, S25

Lovell, D. J., 497

Lozovaya, V., S47

Lozoya-Saldaña, H., S25

Lu, F., S110

Lu, G., S39

Lu, J. Y., S9

Lu, R., S129

Lu, S.-E., S49

Lu, T. Y., S9

Lucas, W. J., S75

Luce, K., S49

Lueth, P., S41

Lumsden, R. D., 1032

Luo, Y., S49

Lupien, S. L., S21

Lupin, anthracnose, genetics and morphology, 986

Luster, D. G., 833, S29

Lutton, E., S54

Lutz, M. P., S49

Lycopersicon hirsutum (see also Tomato) —bacterial canker, resistance loci in strain, 504

-L. pennellii, late blight, quantitative resistance, S77

Lydiate, D. J., 1134

Lygin, A., S47

Lynch, R. E., S33, S149

Lyons, M. T., S49

Lysobacter enzymogenes, chitinases and glucanases, regulation, S91

Ma, Z., 519

Maas, J. L., S49

Maccheroni, W., Jr., 464

MacDonald, W. L., S94

MacGuidwin, A., S61

Machado, C., S62

Machado, M. A., 1048, S86

MacKenzie, S. J., 1245, S50, S55

MacKey, J., 710

Macrophomina phaseolina, on bean, isolates in Puerto Rico and Dominican Republic, S119

Madden, L. V., 1005, S21, S23, S41, S59, S72, S101

Madsen, B., S61

Magarey, P. A., S41

Magee, J. B., S77

Magnaporthe grisea

- appressoria, defective in mutants, S7

-appressorial penetration and hyphal growth, transcription factor, S63

-Avr-Pita gene family, evolution, S41

-chromosome 7, sequencing, S80

-on perennial ryegrass, epidemics and primary inoculum, S34

-phylogenetic analyses, S81

- protein kinase, cAMP-dependent, S42

-on rice: chromosome mapping, S19; genes, S47; nontoxic protection technology, 378; quantification during infection, PCR and northern blot analyses, 870 ; resistance mechanism, silicon cell wall fortification, 1095

-on tall fescue, resistance components, S152

-on wheat, gene-for-gene relation, 1182

Magnus, H., 710

Mahaffee, W. F., S50, S67, S70, S74, S100

Mahuku, G. S., 580, S50

Maier, T., S27, S37, S85

Main, C. E., S124

Mair, J., S54

Maisonneuve, B., 169

Maize (see also Corn)

-aflatoxin-resistant genotypes, proteome analysis, 1084

Maize chlorotic dwarf virus, genome sequence and polyprotein cleavage, S14

Maize fine streak virus, new leafhopper-transmitted rhabdovirus, 1167

Maize necrotic streak virus, tombusvirus relation, S68

Maize streak virus

-distribution in leafhopper, monitoring, 65

-on wheat, sequence characterization, 81

Malmstrom, C. M., S50

Maloney, P. E., 597

Malus spp., scab, formae speciales, 314

Malvick, D., S50, S138

Management

—bacterial diseases, copper role, S107

- methods of integration, perspectives, in Cuba, S135

—nematode: Florida landscape, S107, perennial ornamentals, S107

—phytosanitary issues, S111

-rice diseases, antagonistic bacteria, S110

Manceau, C., 1077

Mandal, B., S50, S51, S150

Manfio, G. P., S51

Manganese, oxidation, pathogenic fungi, S80

Mango 
-bacterial apical necrosis, copper resistance, plasmid encoding, 909

-fruit disease severity, classification, S128

-Fusarium decemcellulare on, fungicides for control, S117

Manjunath, K. L., S133

Manker, D., S55

Manning, V. A., S51

Mannitol, fungal metabolism, plant-pathogen interaction, S83

Manuscript preparation, author's guide, 7

Maor, R., 590

Marais, L. J., S51

Marbán-Mendoza, N., S130, S133

Marcell, L. M., 1015

Marco, Y., 1142

Marcone, C., S45

Marek, S. M., A1024, A1025

Marett, C. C., S138, S140

Maribona, R., S116, S124, S132

Marigold, Alternaria sp. on, detection, S119

Marín, M., S131

Mark, G. L., S35

Marøy, A. G.,

Marques, L. L. R., S51

Marrakchi, M., 563, S30

Martin, D. (Cuba), S124

Martin, D. L., S38, S84, S88, S138, S141, S152

Martin, D. P. (South Africa), 81

Martin, F. N., 232, 1356, S40, S51

Martin, G. B., S102

Martin, R. R., S52, S65, S82

Martin, S. B., S52

Martínez, B., S118, S128, S130

Martinez, E., S65, S123, S124

Martínez, J. (Cuba), S132

Martinez, J. P. (Oregon), S52

Martínez, Y., S121, S126

Martinez-Ochoa, N., S50, S150

Martínez-Soriano, J. P., S123, S125

Martínez Zubiaur, Y., S132, S136

Martini, M., S45, S52, S91

Martyn, R. D., S34, S116

Marvel, J. K., S142

Mason, P. A., S52

Masters, C. M., S111

Matheron, M. E., S52

Mathews, D. M., S83

Matthews, K. R., S100

Matthysse, A. G., S97

Matveeva, E. V., S52

Maupin, L. M., S53

Mavrodi, D. V., S53

Mavrodi, O. V., S53

Mavrodieva, V., S53

Maximum pest limit, concept, $\mathrm{S} 100$

Maxwell, D. P., 487, 637, S33, S54, S56, S74, S75, S125, S127, S131

Maxwell, M. D., S127

May, K. J., S53

Mayama, S., 1182

Mayfield, C. T., S79

Maymon, M., 164

Mayoral, A., S33

Mazid, M. A., S62

Mazur, E., S39

Mazyad, H. M., S75

Mazzola, M., 1363, 1301, S27, S53, S64

McCartney, C. A., 138

McClung, C., 32

McClure, M. A., S18

McDaniel, R. G., S150

McDonald, B. A., 1175, 946

McDonald, G. I., S36, S73, S95

McEvoy, J. L., S63, S67

McFadden, A., S22, S53, S77

McGee, D. C., S56

McGill, M. A., S53

McGovern, R. J., S145, S150
McGrath, M. J., S53

McGrath, M. T., S144, S146

McGuire, I. C., S94

McInroy, J. A., 1329

McKenna, L., S48, S69

McKenzie, D., S108

McKirdy, S. J., 321

McLane, H., S76

McLaughlin, W., S127

McLean, K. S., S33, S149, S150, S151

McManus, P. S., S29, S83

McMillan, R. T., Jr., S54

McMillan, W. A., S54, S110

McMullen, M., S139

McPherson, M., S76

McSorley, R., S85, S107

McSpadden Gardener, B. B., 129, S54, S99

McWilliams, M. G., S30, S54

Meachen, E. W., S112

Meazza, G., S85

Medicinal herbs, shade-grown, diseases of, S68

Medina Pitalúa, J. L., S120

Meinhardt, S. W., 38, 527, S3

Mejia, L., S54, S127, S131

Melaleuca alternifolia, oil use in disease control, $\mathrm{S} 12$

Melcher, U., S90

Melchior, G. L., S54, S55, S87

Melgarejo, P., 863

Mellich, T. A., S60

Meloidogyne spp.

-M. chitwoodi, Meloidogyne spp. comparison, ribosomal integenic spacer, 884

$-M$. graminicola, on rice, yield effect in Bangladesh, S62

-M. incognita: Crotalaria juncea amendment effect, S85; parasitism genes, in esophageal glands, S37; on Psidium guajava, soil microflora, Venezuela, S131; on soybean, cultivar effect in Illinois, S3; on tomato, soil amendments, $\mathrm{S} 84$

Melon, monosporascus root rot, biocontrol in Taiwan, S48

Melouk, H. A., S55, S72

Melton, T. A., S79

Melzer, M. J., S151

Melzer, M. S., 780, S19

Méndez, A., S131

Mendoza-Zamora, C., S133

Menelas, B., S55

Meng, X., S55

Menge, J. A., 850, 857

Mercier, J., S55

Meredith, F. I., S29

Merrifield, K., S77

Mertely, J. C., S50, S55

Mesa, M. E., S135

Mesocriconema sp., on bentgrass, in Alabama, S33

Methyl bromide alternatives

-apple growth in replant soils, management, symposium, 1363

-fumigant emissions, symposium, 1344

- fumigants and drip irrigation systems, symposium, 1349

—pre-plant fumigation, symposium, 1337

-realities and concluding remarks, symposium, 1373

—-soilborne pests, vegetable production systems, nonchemical management, symposium, 1367

- strawberry root pathogen control, biological approaches, symposium, 1356

—-symposium introduction, 1334

Metzger, M. S., S55

Meulia, T., 1167

Mew, T. W., 32, S110

Meyer, F. W., S145, S146

Meyer, S. (North Dakota), S139

Meyer, S. L. F. (Maryland), S55
Miao, H., S76

Miao, Z. Q., S56

Micales, J. A., S56

Michailides, T. J., 406, 519, S14, S20, S49, S60

Michalakis, Y., 576

Michel, F. C., Jr., S13

Michelsen, P. M., S27

Michener, P. M., S11, S56

Michoski, C. E., S7

Microbiology, soil, species composition in North Carolina, S30

Microdochium nivale, on bluegrass and creeping bentgrass, incidence in mixed stand, S22

Microsphaera pulchra, on dogwood, protein analysis, $\mathrm{S} 4$

Migheli, Q., 936

Miklas, P. N., S44

Mila, A. L., S56, S101, S102

Milde, B. N., S33

Milgroom, M. G., S94

Milián, J. P., S124

Miller, A. J., S99

Miller, C. D., S38

Miller, D. R., S56

Miller, F., S39

Miller, G., S80

Miller, J., S68, S78, S139

Miller, S. A., S90

Miller, T. C., S36

Miller, W. A., S48

Millett, S. M., S56

Mills, D., S20, S110

Milne, R. G., 288

Milus, E., S56, S84

Mims, C. W., 803, S57

Min, B. E., 156

Minogue, T., S57, S97, S144

Minsavage, G. V., 273, S36, S57

Mirafiori lettuce virus, Lettuce big-vein virus comparison

- cover photo, March

-etiology and transmission, 288

Miranda, E., S121, S122, S127

Miranda, I., S118

Mireles, M., S128

Mirkov, T. E., S36

Mitchell, D. J., S27

Mitchell, T., S80

Mitkowski, N. A., S10

Mitter, V., S2

Mizumoto, C. Y., S4

Mmbaga, M. T., S4, S57

Model

—anthracnose on lupin, spatiotemporal, 1110

-artificial neural network, analytical tool, S101

-Burkholderia, soil diversity, farming system variation, S24

- disease prediction using leaf wetness, binary logistic regression, $\mathrm{S} 64$

-Fusarium growth in corn ears, mathematical, 534

-Internet-based fungal pathogen database, letter to editor, 232

-linear, designed experiments, S101

-MARYBLYT, improvements, S19

-raindrop kinetic energy, splash dispersal, 497

-rainfall-based, Stagonospora nodorum on wheat seed, 511

Moënne-Loccoz, Y., S68, S69

Mohamed, E. F., S23

Molina, J., S36

Momol, M. T., S6, S60, S108

Monci, F., 842

Mondal, S. N., 1267, S57

Mondjana, A. M., S44, S140

Monfort, W. S., S151

Monilinia spp.

- M. fructicola: germ tube development, redox regulation, A1024; on prune, inoculum poten- 
tial and cultural practice, S49; on prune, latent infection, S49; on stone fruits, ethylene exposure, S62; on sweet cherry, fungicide resistance and alternate row-spraying potential, S2; transformation by Agrobacterium tumefaciens, green fluorescent protein, A1025

-M. vaccinii-corymbosi: on blueberry, biocontrol of flower infection, S73; on blueberry, clone variation, S64; on blueberry, infection factors, 1104; on blueberry, stigmatic exudate effect, S59; pseudosclerotial distribution, cultivation effect, 877

Monks, D. W., S25

Montero, N., S121

Montes, N., S57

Montesinos, E., 99

Montilla, J., S128

Moore, M. K., S14

Moore, P., S76

Moore, W. F., S148

Moorman, G. W., 232, S28, S58, S144

Morales, F., S109, S119

Morales-Payan, J. P., S58

Moreira, A. J. A., S32, S58, S140

Morello, J. E., S58

Moreno Díaz de la Espina, S., S114

Moreno Onorato, J., S117

Morey, K., S45

Morgan, D. P., S49

Morgan, G. W., S58

Morgan, W. R., S102

Morgan-Jones, G., S151

Morin, S., S96, S116

Moriones, E., 842

Morissette, D., S144

Morris, J. B., S84

Morris, P. F., A1025

Morris, R. F., S152

Mosqueda, M., S133, S117

Motoyama, T., 75

Moyer, J. W., S59

Mozafari, J., 87

Mozzoni, L. A., S71

Mueller, D. S., S58

Mueller, J. D. (South Carolina), S80

Mueller, J. P. (California), 1349, S58

Mullinix, K., 1363

Mullins, E., 232, S103

Mulrooney, R. P., S144, S151

Mundt, C. C., 617, 624, 1175, S95, S96

Muñiz, Y., S118, S125, S128

Munkvold, G. P., S64

Muñoz, F. R., S117

Munõz, J., 580

Murillo, J., 909

Murphy, J., S146

Murray, T. D., 703, S137

Mushrooms, maitake, oyster, and reishi, leachate effect on bacteria, S151

Mycofumigation, soilborne diseases, S31

Mycorrhizae, arbuscular, plant defense genes, S144

Mycosphaerella spp.

-M. citri: on citrus: pseudothecia and ascospores, environment effect, S57; Mycosphaerella citri on citrus, pseudothecium and ascospores, factors, 1267

-M. fijiensis: alternate gene control methods, S136; on banana, detached leaf assay, S135; on banana, fungicide sensitivity, in Cuba, S131; on Musa spp., plant-pathogen interaction, S116; physiology and morphology, in Ecuador, S124

-M. graminicola: field populations, genetic structure, 946 mutation in coding and flanking regions, $\mathrm{S} 81$; on wheat, cultivar mixture effect, 617; on wheat, gene-for-gene relation, 439; on wheat, isolate aggressiveness, 624; on wheat, race-specific resistance, 138; on wheat, resistance and molecular mapping, S2; on wheat, resistance genes, S68; on wheat, sexual reproduction frequency, 1175

Mycotoxin

-aflatoxin: Aspergillus spp., in Mississippi Delta, S1; corn and peanuts, drought tolerance, S33; maize genotypes resistant to, proteome analysis, 1084; role of host for Aspergillus and Arabidopsis, S33

—fumonisin, Fusarium verticillioides on corn, $\mathrm{S} 25$

-ochratoxin, aerosol exposure, S93

Myers, D. S., S150

Myles, L., S4

Nagai, C., S76

Nagata, R. T., S148

Nahkla, M. K., 487

Naidu, R. A., 729, S58

Nakahara, K., 542

Nakhla, M. K., S54, S74, S75, S127, S131

Nalim, F. A., S145

Nameth, S. T., S134

Naranjo, M., S116, S128

Nason, J. D., S40

Navas-Castillo, J., 842

Nazaret, S., S69

Neate, S., S7

Nectria haematococca, gene for pathogenicity and catabolic activity, for pea, S70

Nelson, B., S8, S137

Nelson, R., S109, S131

Nelson, S. D., 1349

Nematicides

—DiTera, mode of action, S105

- field development experiences, S105

-Laetiporus sulphureus and Ganoderma lucidium as source, S70

-lesion nematode control, biologically derived, $\mathrm{S} 72$

—root tip exudate effect, legumes, S18

Nematodes

—foliar, nursery production, S107

- ornamentals, field diagnosis, S107

-root-associated microbes antagonistic to, detection, S55

Nemchinov, L. G., S59, S105

Neninger, H., S115, S128, S129

Neotyphodium spp., on grasses, endophyte producing ergovaline, S62

NeSmith, D. S., 877

Nesmith, W. C., 400, S35

Nester, S. E., S142

Neuman, M. F., S59

Neves-Martins, J., 986

New, S. L., S59

Neyra, M., S122

Ngugi, H. K., 877, 1104, S59, S73

Niblack, T. L., 456, S7, S16, S38, S59, S88

Niblett, C. L., S133

Nichols, E. S., S100

Nicol, R. W., 534

Nicolas, P., 308

Nicole, M., 336

Nicotiana spp., mildew, gnotobiotic associations, 400

Niederhauser, J. S., 688

Nigel, H., S127

Nikolaeva, E. V., S52

Niks, R. E., S120

Nilpanit, N., S110

Nimtz, M., S28

Nissinen, R. M., S59

Nita, M., S59

Nitao, J. K., S55

Nitric oxide, synthase in plants, comparison in animals, S87

Nitzan, N., 827

Nodulisporium sp., on lemon, in Arizona, S52

Noling, J. W., 1373
Nomura, K., S92

Nordheim, E. V., S78

Norelli, J. L., S147

Norman, D. J., S60

Novacky, A. J., 456

Ntahimpera, N., S60

Nunes, C., 281

Nunez, J., S55, S70

Nuno V. P. Ribeiro, L., S118, S132

Nutter, F. W., Jr., 478, 668, S24, S32, S45, S55, S58, S60, S138, S140

Oak (see also Quercus), sudden death

- eradication in Oregon, S30

- survey in Oregon, S54

- tree susceptibility assessment, S33

Oberle, C. S., S87

Obituary, Shu-Huang Ou, 32

Obradovic, A., S6, S60, S108

O'Brian, G. R., S73

O'Brien, S., S89

Obsuwan, K., S27

Ocamb, C. M., S100

Ockey, S. C., S60

O'Connell, M., 1110

O'Connell, N. V., S5

Oda, C., S76

Odontoglossum ringspot virus, on orchid, detection using DNA biosensors, 654

Odvody, G., S57

Oesch, N. W., S52

Ofelia López Mesa, M., S126

Ogram, A., S21

Oh, C.-S., S60

Oh, H. S., 1182

Ojiambo, P. S., A1025

Okubara, P. A., S61

Olatinwo, R. O., S61

Olaya, G., S61, S111

Oldach, K., S28

Oleas, A. R., S24

Olivain, C., 936

Oliveira, A. C., 1048

Oliveira, H., 986

Olivera Rodríguez, H., S120

Olpidium brassicae; vector for Mirafiori lettuce virus virus and Lettuce big-vein virus, 288

Olson, B. D., S22, S53, S61, S77

Olson, M. E., S51

Olson, S. M., S6, S60

Olson, T. N., S42

Omer, M., S61

O’Neill, N. R., S64, S83

Ong, K. L., S61

Onion

- center rot, mulch and irrigation effect, S149

- foliar pathogens, spray programs, cost benefit, S44

—purple blotch, resistance induced, S4

Oomycetes, host range, flower production greenhouses, S146

Opgenorth, D., 721

Ophiosphaerella korrae, on bermudagrass, isolate aggressiveness in populations, S38

Ophiostoma spp., wood products and genetics, S95

Orange, green mold, Armicarb-100, S90

Ordosgoitti, A., S129

Orellana Pérez, P., S125

Ornamentals, chlorine and hydrogen dioxide toxicity, S148

Orobanche

-O. aegyptiaca, Fusarium spp., hypervirulence enhanced, indole-3-acetic acid, 590

-O. crenata, variation, in Spain and Israel, 1262

-O. cumana, on soybean, resistance activation by benzothiadiazole, 59

-O. ramosa, on tomato, triiodobenzoic acid effect, S34 
Oropeza, C., S118, S126

Ortego, F., S114

Ortiz, O., S109

Ortíz, U., S117

Ortiz-Ribbing, L. M., S61

Osbourn, A. E., S103

Oshima, M., 75

Ospina-Giraldo, M., A1024, S68, S103

Osterbauer, N., S30, S54

Ostrinia nubilalis, on corn, interaction with gray leaf spot in stalk rot, S5

O'Toole, G., S98

Otrosina, W., S95

Oudemans, P. V., S18, S61, S62, S143, S145 S146

Outreach

-APSnet Education Center, new resource, S113

- symptoms and sign demonstration, S113

Ownley, B. H., S9, S31, S98

Ozaki, K., 542

Özbek, E., S96

Ozdemir, Z., S62

Ozmon, E. A., 755

Pace, P. F., S153

Pacumbaba, R. O., Jr., S151

Pacumbaba, R. P., S151

Padgett, G. B., S151

Padgham, J. L., S62

Padilla, D., S129

Paecilomyces lilacinus, biocontrol product from, S4

Paez, G. T., S24

Pagani, C. M., S62

Paillet, F. L., S94

Pain, N. A., S135

Pairol, A., S123

Palmateer, A. J., S151

Palmieri, M., S116

Palou, L., S62

Palukaitis, P., 51

Pamplona, R., S110

Pan, Y.-B., S32

Pan, Z., A1025

Panaccione, D. G., S62

Pandelova, I., S51

Panicum virgatum, reservoir in range grasses, S26

Pantoea spp.

-P. agglomerans: on apple and pear, biocontrol in orchards, 1202; on corn leaves, 1015; on cranberry, characterization, $\mathrm{S} 83$

$-P$. stewartii: biofilm formation, quorum sensing, S57; on corn, biofilms and surface attachments, S97; on sweet corn, quorum sensing regulation, $\mathrm{S} 144$

Papaya

- transgenic: technology transfer in Venezuela S120; virus mixtures, effect in Puerto Rico, S25virus resistance, $\mathrm{S} 122$

Papaya ringspot virus, resistance in Florida, S18

Papiernik, S. K., 1344

Pappu, H. R., S50, S51

Paradkar, M. R., S73

Parasitism, evolution, essential genes, S103

Parisi, L., 314

Park, E. (Maryland), S63

Park, E. W. (Korea), 1095

Park, G., S63

Park, J.-H., S62

Parke, J. L., S47, S63

Parker, D. M., S63

Parker, J., S129

Parker, S. R., 497

Parkin, I. A. P., 1134

Parks, W. J., S150

Parsons, C., S56

Partipilo, H. M., S63

Partridge, D. E., S64
Partridge, J. E., S8, S26

Pasteuria penetrans

-in soil, detection with specific PCR, S21

- vegetative and sporulating structures, S28

Pastor-Corrales, M. A., S64

Pataky, J. K., S11, S56, S64

Pataky, N., S5

Pathogenicity, genetics in plants, $\mathrm{S} 103$

Patil, V., 710

Paul, P. A., S64

Paulin, J. P., 1077

Paulitz, T. C., 769, S64, S74

Paull, R., S76

Paulus, A. O., S129

Pavan, M. A., 563

Payne, G. A., S73

Payton, M. E., 347, S38

Pazos, V., S118, S124, S130

Pea, Mycosphaerella blight, dynamics, S90

Peach

-leaf rust, low-chill effect in subtropical climate, $\mathrm{S} 132$

—nematodes, Illinois, S71

-Plum pox virus, aphid vector competence, S29

-replant disorder, specificity, S10

—scab, captan/sulfur tank-mixes, S76

Peacock, A. D., S49

Peanut

-Aspergillus on seed, oxygenases, S81

-clump disease, pecluviruses, West Africa and India, S58

-disease and yield, in-furrow treatments, $\mathrm{S} 12$

- early leaf spot: fungicide factors, S149; peanut-corn intercropping effect, S21

-leaf spot: southern stem rot, flutolanil for, S12; tillage practice and fungicide, S151

-rust, fungicides in Florida, S150

- Sclerotinia blight, fluazinam and biocontrol agent forcontrol, S64

- Sclerotinia minor, relative humidity effect, S55

— southern stem rot: epidemics, S152; fungicides and environment, S102; fungicide and seeding factors, S74

Pear

-brown spot, relative humidity and wetness period, 99

-decline, phytoplasma in California, pear psylla, 1218

-Phacidiopycnis rot, postharvest, S88

- Phytophthora spp. in fruit, irrigation water in Washington, 1210

- postharvest decay, fungus and chemical control, 281

Pearl millet, toxigenic fungi, host differences, S87

Peart, J. R., S129

Pecan, leaf and nut scab, fungicide combination, S74

Pedersen, P., S140

Pedersen, W., S47, S139

Peever, T. L., 794, 1210, S7, S36

Peltier, A. J., S31

Peñalver Martinez, N., S126

Peng, G., S9

Penicillium spp., on apple and citrus fruit, tissue acidification, S67

$-P$. digitatum, on grapefruit, resistance induced by yeast, 393

-P. expansum: on apple, postharvest, inoculum cycling, S145; on apple, postharvest decay, biocontrol, S39; on apple, resistance induced by, 900

$-P$. oxalicum, biocontrol for tomato Fusarium wilt, 863

Penman, L. N., S64

Pennypacker, B. W., S42

Pentastiridius sp., on sugar beet, syndrome "basses richesses," relation, 384

Pepper -bacterial spot, neem oil and fish emulsion applications, $\mathrm{S} 1$

-Phytophthora blight, resistance, S5

Peral, R., S119

Perales Rosas, D., S130

Peralta, E. L., S115, S118, S122, S123, S124, S126, S130, S134

Percich, J. A., S24

Percich, J. E., S43

Peres, N. A. R., S64

Pérez Miceli, A., S127

Pérez Ponce, J., S125

Pérez Vicente, L., S135, S136

Pérez, B., S65, S122

Pérez, C., S3

Pérez, I., S134

Pérez, J., S115, S118, S130

Pérez, L., S114, S131, S132

Pérez, M., S117, S119, S131, S133, S134

Pérez, N., S132

Pérez, S., S130

Pérez, Y., S122

Pérez-García, A., 909

Pérez-Pérez, E., S131

Pérez-Vicente, L., S115

Perkins, J. M., S53

Pernezny, K., S118

Peronospora spp.

-P. arborscens, on poppy, epidemiology, S101

-P. tabacina: on Nicotiana spp., gnotobiotic associations, 400; on tobacco, isolate genetic uniformity, 1236; on tobacco, restriction fragment length polymorphism probes, 1227; on tobacco, sporulation on roots, cover photo, April

Perry, R. N., 378, S105

Pesic-Vanesbroeck, Z., S25

Pestana, M., S132

Peteira, B., S126, S130

Peteira Delgado, B., S118

Peters, D., 603

Peterschmitt, M., 65

Peterson, G. L., 217

Pethybridge, S. J., S35, S65

Petunia, new virus, $\mathrm{S} 134$

Petzoldt, C. H., S108

Peypelut, M., 563

Pfeiffer, T. W., 446

Pfender, W. F., S65

Pfund, C., S65

Phacidiopycnis piri, on pear, infection court, S88

Phaeocryptopus gaeumannii, on Douglas-fir

- colonization quantification, 112

-epidemic creation, S95

Phaeoisariopsis griseola, on bean, Afro-Andean group, molecular markers, 580

Phaeomoniella chlamydospora, on grape

-pruning wounds and Phaeoacremonium sp., S32

-pycnidial state in California, S24

Phakopsora pachyrhizi, urediniospore germination, sequence tags, S66

Pharand, B., 424

Pharr, D. M., S83

Phaseolus vulgaris

-Fusarium oxysporum, detection in plants using DNA procedure, 237

-mosaic virus resistance, genotypes, S133

-Rhizoctonia solani, in Mexico, S133

-rust, virulence distribution in field, 755

-virus epidemic, Great Lakes region, S44

Phialophora gregata, on soybean

-genotype distribution, cultivar, S50

— soil pH effect, S43

-symptom modification, S42

Philion, V., 769, S145

Philip, R., S106

Phillips, D. V., 785

Phillips, M. S., 884 
Philogène, B. J. R., S7

Phoma spp., on alfalfa, chemical control in Alberta, S85

$-P$. ligulicola, on pyrethrum, isolates in Tasmania, S65

$-P$. medicaginis, on alfalfa, molecular variability and pathogenesis, $\mathrm{S} 12$

Phomopsis spp.

-P. helianthi, on sunflower, molecular variability, 308

-P. longicolla, on soybean, weed hosts in Arkansas, S150

-P. vaccinii, on cranberry, probable cause, $\mathrm{S} 12$

Phyllosphere

- corn, bacterial colonization of leaves, 1015

- dispersal and epidemic velocity, scale effect, S96

Phytophthora spp.: in China, survey, S89; on citrus, hypovirulent isolate protection, S16 elicitin genes, S77; on European beech, cankers, A1024; fatty acid production, identification use, S21; genomics in plant interactions, S102; in irrigation water recycling system, Virginia, S11; isolation from irrigation water, membrane filters, 610; on ornamentals, dieback diseases, S47; on pear, irrigation water in Washington, 1210; recycled irrigation water, significance in ornamental production, S143 recycled water irrigation system, Virginia, S142; on soybean, detection with PCR assay, 217

-P. capsici: on bell pepper, resistance, S5; biorationals for control, screening, $\mathrm{S} 71$; on $\mathrm{cu}-$ cumber, cover photo, June; in Florida, characterization, S81; on pepper, detection in Florida $\mathrm{S} 27$; on pepper, mefenoxam and timing intervals, S143; on pepper, resistance, S40; on pepper, varietal resistance, S144; on pepper and cucurbits, genetics and control, S139; on pepper and squash, mefenoxam sensitivity, S11; spatiotemporal enetic structure, disease management and management, symposium, 681; sporangia and zoospores, oxamide effect, S89

- P. cinnamomi: on Banksia attenuata, benzoic acid as pre-treatment, S86; on loblolly pine, in Alabama, $\mathrm{S} 85 ; P$. citricola comparison, on walnut, resistance and grafts, S10

$-P$. infestans: genetic variability and markers, S137; in herbarium specimens, mitochondrial DNA haplotype, S53; on petunia and Nicotiana, S145; population in Israel, major changes from 1983 to 2000, 300; on potato, climate relation in Cuba, S134; on potato Gavel 75 for control, S22; on potato, genetic instability in isolates, S32; on potato, genetics in Costa Rica, S30; on potato, in Mexico, S25; on potato, seedborne clonal lineages, S63; on potato, in Taiwan, S143; on potato, transmission, S63; sporangia and zoospore survival in water, S66; on tomato and potato, genetic diversity in North Carolina, 1189

- P. kelmania, molecular characterization, other new species, A1026

-P. megakarya, on cacao, in Papua New Guinea, $\mathrm{S} 2$

-P. nicotianae: genetic variability, $\mathrm{PCR}$ analysis, S127; on pineapple, resistance selection method, S133; on tobacco, variability in Cuba, S133

-P. parasitica: on citrus, biocontrol with Pseudomonas putida, 850; zoospore distribution in water, irrigation relation, $\mathrm{S} 84$

- $P$. ramorum: on ericaceous species, $\mathrm{S} 81$; on forest trees, cankers in California and Oregon, $\mathrm{S} 17$; on Vaccinium, in California and Oregon, S63

-P.sojae: population shift, management, S20; on soybean, PDR-5-like transporters, A1025; on soybean, resistance and trait loci, S11; on soybean, resistance locus, S10

Phytoplasma —alfalfa witches'-broom, identified in Oman, 1038

-elm yellows group, classification and protein gene sequence, $\mathrm{S} 45$

- pear decline, California, psylla relation, 1218

- on sugar beet, "basses richesses," 384

-typing, PCR and genetic sequences, S82

Phytotoxin, chlorosis-inducing, tan spot of wheat, 527

Piccinni, G., S10

Pichardo, T., S122

Pichia guilermondii, on strawberry, biocontrol agent, 976

Picton, D. D., S65

Pierson, E. A., S58

Pierson, L. S., III, S58, S86

Pike, S. M., 456

Pilowsky, M., S127

Pineapple

-mealybug wilt, closterovirus, mealybug exposure, 928

-mealybug wilt symptoms, cover photo, September

-nematodes, resistance, S76

-nematodes, resistance and acibenzolar-S-methyl, S15

- transformation genetics, S120

Pinkerton, J. N., S65

Piñón, D., S128

Pinón, M., S126

Pinus spp., anthracnose, tracer, model for spread in field, 1110

$-P$. elliottii, seed treatment, silver nitrate, $\mathrm{S} 20$

-P. jeffreyi, dwarf mistletoe, host interaction in Sierra Nevada, 597

-P. nigra, Sphaeropsis sapinea, systemic resistance, $\mathrm{S} 8$

- P. ponderosa, Douglas-fir comparison, diversity in Cascade Mountains, S36

$-P$. radiata, chips harboring fungi, Chili to USA, S56

-P. strobiformis, blister rust, pathosystem and genetic specificity, 278

Pires, E., S33

Pistachio

-Alternaria late blight, isolate characterizations, 406

-Botryosphaeria blight, carbohydrates, S60

- Botryosphaeria dothidea on, isolate characterization and hosts in California, 519

Pitts, J. A., S76

Plasmopara viticola, on grape

-DMCast refinement, S41

-oospore viability, soil treatments, S42

Plattner, R. D., S19, S67, S93

Plectosporium tabacinum, on pumpkin, in Illinois, S5

Plovanich-Jones, A. E., S92

Plum pox virus, detection and quantification, S75

Podosphaeria leucotricha, on apple, incidence and density relations, 1005

Pogue, G. P., S104

Polashock, J., S61

Poling, E. B., S25

Polityko, V. A., S52

Polymerized chain reaction

-bacterial disease diagnosis, S110

- specimen preparation, S110

Polymyxa graminis, on wheat, temperature and soil matric effect on infection, S17

Pomella, A., 1032

Ponciano, G., S65

Pool, W. M., S109

Poole, E. C., S66

Poplawsky, A. R., S66

Porat, R., 393

Porchas, M., S52

Porter, L. D., S66

Posada, M. L., S66
Postharvest pathology

- biocontrol with Colletotrichum coccodes, 33

-biological management, S106

-blue mold of apple, disease control agents, 900

-Colletotrichum gloeosporioides on avocado, protection mechanisms, 1196

- pear decay, fungus and chemical control, 281

Postman, J. D., S65

Postnikova, E., S2, S66, S72, S110

Potato (see also Solanum spp.)

- aspartic proteases, antimicrobial activity, S33

-bacterial pathogens, diagnostic assay, S25

-begomovirus, in Cuba, S117

-black dot, vegetative compatibility groups in pathogen, 827

- early blight: management in Sudan, S71; partial resistance analysis, S90; strobilurin fungicides, Wisconsin, S71

- early dying, prevention in California, S70

-Fusarium dry rot and silver scurf, biocontrol products, S106

-Fusarium sambucinum, thiabendazole resistance, synthetic peptides, 917

-late blight: compatibility genomics, S77; durable resistance and management, S32; genetic diversity and structure in fungus, North Carolina, 1189; management in Peru, S109; resistance analysis, S16; resistance in Mexican national program, letter to editor, 688; tuber rot and fungicide management, S53; zoxamide and mancozeb, premix, S61

- nematodes, survey in North Dakota, S52

- phytoplasma on, detection and infection, S125

- powdery scab, European and North American isolates, analysis, S67

- Rhizoctonia, biocontrol and ryegrass rotation, S80

- soilborne disease, cropping systems and soil microbial communities, S44

-Verticillium wilt, coinfection, S61

- virus sanitation, S122

- viruses, detection method, S75

Potato leafroll virus, cultivar resistance, in Cuba, $\mathrm{S} 117$

Potato spindle tuber viroid d, detection, in Cuba, $\mathrm{S} 122$

Potato virus $Y$, ultrastructure, in Egypt, S23

Potter, J. L., S131

Powell, J., S13

Powelson, M. L., S63

Powers, K., S8

Powers, T. O., S29

Pozdnyakova, L., S145

Pradhanang, P., S60

Pratt, R. G., 204, S66

Pratylenchus crenatus, on carrot, spatial distribution effect on yield and quality, S35

Press, C. M., S67, S70, S74

Prischmann, J., S18

Proctor, R. H., S67

Programmed cell death

- apopotic genes, disease protection, S104

- tracheary element differentiation, S103

-victorin role, $\mathrm{S} 104$

PROPLANT, information option, in Cuba, S135

Prosopis spp., pathogens in Mexico and Texas, S46

Provin, E. M., 917

Prunus spp., resistance to gummosis, shot hole, and rust, screening method, S68

Prusky, D., 33, 1196, S67

Pruvost, O., 336

Pryor, B. M., 406, S7

Pseudomonas spp.: antibiotic from, in Ohio, root disease suppression, S54; hydrogen cyanide synthase biosynthetic genes, phylogeny, S68; on leaves, survival and UVR sensitivity, S38; mutagenic DNA repair, ecological fitness, S90

$-P$. aureofaciens, phenazine biosynthesis, regu- 
lator, S86

-P. chlororaphis, biofilm formed by, gene involvement, S51

$-P$. fluorescens: biocontrol, cell stress effect, S69; biofilm on abiotic surfaces, S98; Pythium biocontrol, on alfalfa, S3; in rhizosphere, diacetylphloroglucinol production, population monitoring, 129; root colonizing, genetics, S53

-P. putida: biocontrol agent, Phytophthora parasitica control in citrus, 850; biofilm development, surface development, S97; in soil, effect on soil microbial communities, 857

-P. savastanoi, strain variability, hosts, S71

-P. syringae: on apple, diagnosis by PCR, hrpL gene primers, 1077; on Arabidopsis, hrp-regulated genes, S92; on Arabidopsis, resistance gene RPS4, S90; on cucurbits, detection by PCR, S62; genomics and pathogenicity, S102; on mango, copper resistance, plasmid encoding, 909; phyllosphere and field, S96; plasmid, nucleotide sequence analysis, $\mathrm{S} 79$; races, North Dakota, S139; survival on leaves, S97; on sweet cherry, eradication in bud sticks, S33; syringomycin production, Syr proteins, S49; on tomato, biocontrol, 1284

Pseudoperonospora cubensis, on cucurbit, longdistance forecasting, $\mathrm{S} 124$

Pseudotsuga menziesii, Swiss needle cast, colonization quantification, 112

Puccinia spp., on wheat, infection efficiency, light effect, 1308

$-P$. andropogonis: on big bluestem, fire effect on infection, S6; phylogenetic analysis, S79

-P. coronata: on barley, resistance sources, 1064; on oat, phenotypic recurrent selection, S12

-P. dioicae, on Erigeron strigosus, burning and nutrient additions, S18

$-P$. graminis, on ryegrass, nonparametric spatial analysis, S65

$-P$. hemerocallidis, on daylily, temperature effect, S58

$-P$. jaceae, on yellow starthistle, teliospore germination factors 355

- P. sorghi, on sweet corn, resistance, $\mathrm{S} 11$

-P. striiformis, epidemics and races in North America, S14

-P. triticina: on wheat, resistance, inbred lines, $\mathrm{S} 75$; on wheat, uredospore production, carbon and nitrogen relation to lesion size and density, 762

-P. tritici-repentis, on wheat, race 1 reaction to toxins, cover photo, January

Pujol, M., S119, S131, S132

Pujol Ferrer, M., S119

Pumpkin, Plectosporium blight, in Illinois, S5

Purcell, A. H., S3

Pyrenophora spp.

-P. teres on barley, transformation, S7

$-P$. tritici-repentis host-selective toxin, analysis,

S52; host-selective toxin, S51; host-selective

toxin, new race, $\mathrm{S} 3$; toxin, amino acid residues, S51; on wheat, race 1, toxin sensitivity, 38 ; on wheat, tan spot toxin, chromosome location, 527

Pyricularia grisea

-on perennial ryegrass, isolate relations, 245 , 1253

- on rice, multilocus gene genealogy, S16

Pythium spp.

—on alfalfa, biocontrol by Pseudomonas, S3

-on apple and wheat, new species in Washington, S64

-on cotton, damping-off control with Trichoderma, 177

-on greenhouse floral crops, Pennsylvania, S144

-isolation from irrigation water, membrane filters, 610 -metalaxyl sensitivity in isolates, $\mathrm{S} 147$

- populations, genetic markers, S28

— propamocarb resistance, $\mathrm{S} 58$

Qi, M., 870

Qi, W., S145

Qiu, D., S67

Qiu, W. P., S67

Qu, X. S., S67

Quagliotto, L., S3

Quan, S., S131

Quarantine, Guignardia citricarpa on woody plants, 464

Quercus spp. (see also Oak), mortality, crown, and decline, Minnesota, S43

Quiala, I., S122

Quijada, O., S131

Quiñones, M., S121, S126, S132, S136

Quintero, C., S133

Quintero Fernández, S., S120

Quirino, B. F., S67

Raaijmakers, J. M., S21, S99

Rabedeaux, P. F., S67

Rahme, L. G., S103

Raina, R., S103

Ralphs, M. H., S70

Ralstonia solanacearum

-on Arabidopsis, ethylene-insensitive mutant, 1142

- detection methods, biovar differentiation, S52

-ELISA method for detection, S74

- on geranium, race 3, Guatemala, S42

- green fluorescent protein, virulence gene expression, $\mathrm{S} 48$

—pathogen motility, S3

- strains and fluorescent protein, pathogenesis, S19

Ramachandran, P., S71

Ramette, A., S68

Ramírez, I., S126

Ramírez, P., S125, S127

Ramon, M. C., S18

Ramos Zayas, J. A., S136

Ramos, B., 237

Ramos, P., S117, S119

Ramos-Leal, M., S132

Rand, R. E., S105

Rane, K. K., S34

Rang, H., S4

Rascoe, J., S82

Rasmussen, J. B., 38, S7

Raspberry, Tomato ringspot virus and Xiphinema americanum on, detection and management, S65

Rathayibacter spp., genomic fingerprinting, amplified fragment length polymorphism, S2

Rathbone, M. C., S145

Rauyaree, P., S68, S103

Ravva, S., S21

Ray, S., S68

Re, E. B., S10

Rea, W., S151

Reade, R., 87

Rebordinos, L., S82

Rechcigl, N. A., S107

Recorbet, G., 936

Red clover necrotic mosaic virus, gene silenced transgenic plants, methylation, S86

Reddy, M. S., 1329

Redinbaugh, M. G., 1167, S14, S68

Redondo, E., 169

Reed, A. N., S46

Reedy, R. M., S91

Reeleder, R. D., S68

Reeser, P. W., S17, S95

Regnault-Roger, C., S7

Reid, L. M., 534, S7

Reilly, C. C., S68
Reina, J., 842

Remphrey, W. R., S15

Resistance

-alfalfa to Sclerotium rolfsii and Sclerotinia trifoliorum, 204

-apoptotic regulatory factors, $\mathrm{S} 104$

- barley to crown rust, 1064

—barley to scald, near-isogenic lines, 710

- Botrytis cinerea to dicarboximide, 75

- Brassica spp. to black rot, race-specific resistance inheritance, 1134

- chickpea to Didymella rabiei, biometric analysis, 417

- cotton to bacterial blight, near-isogenic lines, 1323

-epistasis analysis, resistance responses, S40

- expression profiling and reverse genetics, S102

-faba bean to rust, histology, 294

-Fusarium sambucinum to thiabendazole, on potato, 917

_-genes, molecular markers, polymorphism, S106

-lettuce to Lettuce mosaic virus, recombinant virus test, 169

- pathogen variation, breeding relation, S121

-rice to bacterial blight, gene mapping, 750

- signal transduction, RPS2 interaction, S67

- sunflower to Orobanche cumana, benzothiadiazole effect, 59

- tomato to: bacterial canker, loci, 504; Fusarium crown and root rot, compost-mediated resistance, 424

- transgenic plants to insects, Cuba crops, S132

- wheat to Septoria tritici blotch, race-specific, 138

-white pine to blister rust, specificity, 278

Restrepo, S., S77

Rethwisch, M. D., S82

Rettler, A., S40

Retzel, E., S106

Reviewers, acknowledgment, 4

Reynaud, B., 65

Rezk, A. A., S75

Rezzonico, F., S69

Rhizobacteria

—negative signaling, S58

- plant growth promoting: diacetylphloroglucinol, 129; resistance induced in Thailand, S39

Rhizobium spp., biofilm formation on surfaces, S27

Rhizoctonia sp., on rice, morphology and physiology, S129

-R. solani: anastomosis group AG-13, 893; anastomosis group-2, sequences and virulence, 43; on collard, velvetbean cover crop effect, S150; on impatiens: composted swine waste effect, S19; web blight, S54; on rice, resistance to Venezuelan isolate, S18; on tobacco, new varieties and lines, S126; on wheat, suppressive soil, anastomosis groups 5 and 8, 1301

Rhizopus oryzae

- cotton, control with Trichoderma, 177

—on mulberry root, enzymes, S89

Rhizosphere

-bicontrol, biotechnology application, S99

- tobacco, soybean, and corn, microbial community differentiation, methyl ester analysis, S61

Rhodes, L. H., S80

Rhynchosporium secalis, on barley

- molecular analysis of inoculation, S28

-resistance and near-isogenic lines, 710

Rice

-bacterial blight, resistance, gene mapping, 750

-blast: defense genes, genomic approach, S39; infection quantification, PCR and northern blot analyses, 70; molecular control, A1024; resistance genes $P i$-ta and $P i$ - $t a^{2}$, A1024; resistance loci, defense response, $\mathrm{S} 46$; resistance mechanism, silicon cell wall fortification, 1095 
—breeding and gene mapping, candidate ESTs, S106

-RSV, detection using RT-PCR, in Korea, S45

—seed infection in Cuba, S128, S129

— sheath blight, transcribed spacer sequence, Arkansas, A1025

- transformation genetics and methodology, fungus and insect resistance, S131

- transgenic, insect resistance, S114

- trifloxystrobin-based fungicide, S148

Richard, J. L., S93

Richard-Molard, M., 384

Richards, K., S96

Richards, T. L., S39

Richardson, P. A., 610, S143

Ricker, M. D., S69

Rideout, S. L., S102, S152

Riggs, R. D., S59, S152

Riley, D., S149

Riley, I. T., 321

Riley, K. L., S14

Riley, M. B., S21, S61

Riley, R. T., S29

Riley, T., 361

Rimé, D., S69

Rimelspach, J. W., S40, S80

Rimmer, R., S47

Risk assessment, concept and the future, $\mathrm{S} 100$

Ristaino, J. B., 181, 1189, S11, S30, S53

Ritchie, D. F., 197, S62, S85, S107

Rivas, E., S130

Rivas, J., S117

Rivas-Davila, M. E., S33

Riveland, N., S140

Rivera Peña, A., 688

Rizkalla, L. R., S69

Rizzo, D. M., 597, S17

Robbertse, B., S102

Robert, C., 762

Roberts, D. P., S48, S55, S69, S143

Roberts, P. D., 273, S27, S36, S81, S132

Roberts, R. G., S88

Roberts, S. J., 105

Robertson, C. L., S69

Robertson, L., S8

Robertson, N. L., S69

Robles, L., S70

Roche, M. M., S67, S70, S74

Rochon, D., 87

Rodrigues, M., S132

Rodríguez, D., S128

Rodríguez, E., S125, S132

Rodríguez, F., S114

Rodriguez, H. A., S18

Rodríguez, J. G., S115, S135

Rodriguez, M. C., S70

Rodríguez, O., S133

Rodríguez, Y., S117, S133

Rodriguez-Alvarado, G., S25

Rodriguez-Kabana, R., S79

Rodríguez Manzano, A., S120

Rodríguez Nodals, A. A., S120

Roeckel-Drevet, P., 308

Roelfs, A. P., S79

Rogers, J. D., S36

Rogers, P. M., S70

Roggero, P., 288

Rohde, W., S126

Rohman, P., S56

Rohrbach, K., S76

Rojas, M. R., 487

Rojas, X., S123

Román, B., 1262

Romberg, M. K., S70

Romero, A. M., 197

Romero, J., S70

Romero, S., S133

Romero-Cova, S., S123

Rooney, S. N., S24, S32
Roossinck, M. J., S89

Roper, M. C., S70

Rosales, I. M., S133

Rosato, Y. B., S51

Rosburg, T., S138

Rose, black spot, fungicides, in Alabama, S8

Rosenberger, D. A., S145, S146

Rosenzweig, N., S71

Rossi, L. A., S112

Rosskopf, E. N., S2, S71

Rothrock, C., S30, S56

Rotylenchulus reniformis, on cotton, fungus infection of eggs, S152

Rouse, D. I., S26

Rouse, R. E., S132

Rouxel, T., 1122

Row, J. M., S140

Rowe, D. E., 204

Rowe, R., S61

Rowhani, A., S3, S71

Roy, A., S71

Roye, M., S127

Royer, M., 65

Rubiales, D., 294, 1262

Rubio Covarrubias, O., 688

Rudolph, R., S74, S148

Ruíz, M., S122

Ruiz-Tapia, J. M., S133

Rupe, J. C., S71

Rush, C. M., 659, 1026, S10, S79

Russell, J. B., S71

Russin, J. S., S3, S149, S152

Rust fungi, obligate-parasitic life style, S103

Rybicki, E. P., 81

Ryder, E. J., S7, S32

Ryegrass, Pyricularia grisea and Rhizoctonia solani interaction, in turf, $\mathrm{S} 82$

Ryu, C.-M., 1329

Ryu, K. H., 156

Saad, A. T., S71

Sabadell, S., S123, S134

Saballos, A., S127

Sabio, C., S127

Saccharomyes sp., antifungal peptide in, postharvest disease control, 33

Saeed, Z. H. M., S71

Safley, C. D., S25

Saftner, R. A., S46, S67

Sagaram, U. S., S72

Saint-Jean, S., S72

Salam, M. U., 1110

Salas, B., S20

Salati, R., 487

Salinas, K. A., S72

Salmonella, plant colonization by, health risk, S21

Salomon, R., 1167, S74

Samac, D., S12

Samad, R. A., 1323

Sampedro, J., S121, S122

Sams, C. E., S9, S49, S63

Samuels, G. J., 1032

Samuels, T. D., S140

Sánchez, S., S121, S122

Sánchez-Campos, S., 842

Sánchez-Cuevas, M. C., S134

Sanchez-Yañez, J. M., S25

Sanders, D. C., S25

Sanders, H., S149

Sandoval, I., S127

Sandoval, L., S131

Sanitation, alternate control measure for virus and bacteria in Cuba, S123

Sanogo, S., 1032, S2, S72, S101

Santos, R., S117, S134

Santoso, A., S8, S137

Sarría, Z., S122

Satovic, Z., 1262
Saude, C., S72

Sauerborn, J., 59

Saunders, J. W., S43

Savard, M., S7

Savelle, A. T., S73

Sawa, Y., S38

Sawchyn, K., S9

Sawyer, S. A., S58

Says-Lesage, V., 308

Schaad, N. W., 721, S2, S42, S52, S66, S72, S110

Schaafsma, A. W., 534

Schadler, D. L., S113

Schardl, C. L., 400, S35, S62

Scheef, E. A., S72

Scheets, K., S68

Scheidegger, K. A., S73

Schelberger, K., S4

Scherer, M., S4

Scherm, H., 631, 877, A1025, 1104, S44, S59, S73, S100

Scheuerell, S. J., S50

Schilder, A. M. C., S29, S61, S86

Schilling, J. S., S73

Schimelfenig, J., S29

Schindelbeck, R. R., S17

Schisler, D. A., S73

Schizaphis graminum, grain crop pest, virus transmission factors, 970

Schlub, R. L., S73

Schmidt, C., S106

Schmidt, M. E., S3, S149

Schmitt, D. P., S15

Schmitt, M., S18

Schnabel, G., S73

Schneider, D. J., S102

Schneider, J. H. M., S83

Schneider, R. W., S11, S69

Schneider, S. M., S10

Schneider, W. L., S75

Schoedel, B., S74

Schoelz, J., 190, S46

Scholl, E. S., S103

Schollmeyer, M., S28

Scholz-Schroeder, B. K., S49

Schouten, A., S99

Schroeder, K. L., S53, S74

Schubert, T. S., S31

Schultheis, J. R., S37

Schulthess, F., 120

Schulze, D. G., S80

Schumann, G. L., S112, S113

Schuster, G. L., S72

Schutte, G. C., 464

Sclerotinia spp., sclerotial survival, California, S88

$-S$. homoeocarpa: on bentgrass, resistance variability, S13; on creeping bentgrass, geographic incidence, S83; nicobifen for control, S73; on turfgrass, fungicides, S10; on turfgrass, geostatistical analysis, S37; on turfgrass, hypovirulence, S19; on turfgrass, thiophanate-methyl and propiconazole, in Ohio, $\mathrm{S} 40$

- S. minor, on lettuce, resistance evaluation, S32

-S. sclerotiorum: on bean, control alternatives, S105; on canola, phylogeography and genotype-symptom association, 785; on canola, plant architecture effect, S40; on dry bean, calcium effect, S18; polygalacturonases, growth modes, S47; on potato, microsatellite markers, Washington, S41; sclerotial viability, fungicides, S48; S. minor relation, hypovirulence, dsRNA transmission, 780; on soybean, clones from legumes and crucifers, New York and Canada, S42; on soybean, resistance selection, $\mathrm{S} 31$; on soybean, soil temperature effect on sclerotia and apothecia, S56

-S. trifoliorum, on alfalfa, relation to Sclerotium resistance, 204 
Sclerotium rolfsii

- on alfalfa, resistance enhanced by Sclerotinia, 204

-on peanut, pod breakdown and calcium, S72

— sclerotium viability, fungicides, S48

- on tomato, soil factors and yield, 181

Sconyers, L. E., S74

Scott, E. S., S42

Scott, J. B., S101

Scott, J. S., S65

Scott, W. D., S74, S152

Sears, J. L., S87

Sebastián, B., S134

Sechler, T. M., S50, S67, S70, S74

Secor, G. A., S137

Sedegui, M., S74

Seebold, K. W., S17, S74, S79, S150, S152

Seeland, T. M., S11

Seem, R. C., 671, 1068, S41

Seguin-Swartz, G., S47

Seifers, D. L., 1167, S74

Seijo, T. E., S150

Semer, C. R., S150

Semighini, C. P., 1048

Senaratna, T., S86

Seo, Y., S75

Septoria spp., on woody perennials, molecular phylogenetic relations, S25

-S. passerinii, on barley, sexual cycle, S30

Serdani, M., S46

Serratia marcescens, on cucurbit, genotypic typing, S90

Sesma, A., 909, S103

Setaria viridis, biocontrol, pathogen strategy, S9

Sether, D. M., 928

Settle, D., S75

Seybold, S. J., S43

Sh Pekhtereva, E., S52

Shah, D. A., 511

Shalaby, A. A., S75

Shaner, G., S75

Sharon, A., 590, 743

Sharpe, A. G., 1134, S47

Shatley, D., 1349

Shatters, R. G., Jr., S36

Shaw, M., S82

She, Y.M., S74

Shealy, R., S106

Shelton, J., S82

Shelton, K. L., S112

Shepherd, L. M., S56

Sherman, D. J., S75

Sherwood, J. E., 210, S6, S28, S43

Sherwood, J. L., 729, S4

Shew, B. B., S21

Shew, H. D., S79

Shi, Q. J., S75

Shibli, R., S34

Shiel, P. J., 694

Shields, E. J., S93

Shier, W. T., S1

Shim, W. B., S76

Shinohara, H., S89

Shishkoff, N., S146

Shoemaker, P. B., 1189, S112

Shon, K. J., S105

Shoop, E., S106

Shtienberg, D., 417, 976

Sidwell, R., S38

Sierra-Suárez, J. M., S132

Sikora, E. J., S76

Sikora, R. A., S41, S98

Sillero, J. C., 294

Simmons, L. J., S76

Simpfendorfer, S., S2

Simpkins, S., S110

Simpson, C. E., S15

Singh, P., A1025

Singleton, L. L., S38, S140
Sipes, B. S., S15, S76

Sirvent, T. M., S76

Sivasithamparam, K., S42, S86

Skaf, J. S., S110

Skaria, M., S76

Skinnes, H., 710

Smart, C. D., S77, S145, A1024

Smiley, G. C., S93

Smiley, R. W., S77

Smith, B. J., 1055, S77, S153

Smith, D. M., 970

Smith, D. R., S95

Smith, G. S., S38

Smith, J. A., S35

Smith, J. P., S25

Smith, K. P., S98

Smith, L. J., S77

Smith, M. A., S83

Smith, R., 378, S22, S53, S77, S103

Smither-Kopperl, M. L., S21, S28

Snook, M. E., S149

Snyder, C. L., 217

Snyder, G., S111

Soeldner, A. H., S74

Soil microbiology

—analysis using fingerprinting, S82

-population monitoring, real-time PCR, S143

Soil solarization, mosaic viral and Phyllosticta foliage diseases, on snapbeans, S79

Soilborne wheat mosaic virus, on winter wheat, inoculation methods, 347

Solanum spp. (see also Potato)

-S. bahamense, new host for plant viruses, S2

-S. phureja, early blight, diploid hybrids, S147

Soliman, A. M., S75

Somai, B. M., 997

Song, S. B., S37

Soon, C. Y, S46

Soppe, R., 1349

Sorensen, B. J., S78

Sorghum

- ergot, weather pattern and prevalence in Texas, 659,1026

-irrigation and charcoal rot relation, S10

Sorghum mosaic virus, on sugarcane, in Louisiana, S32

Soto, M. J., S78, S134

Sotomayor-Ríos, A., S114

Souche, S., 288, 563

Souza, N. L., S64

Soybean

-Agrobacteriumm-mediated germ-line transformation, S53

- Alfalfa mosaic virus and Tobacco streak virus on, symptom changes, S78

- aphid resistance, $\mathrm{S} 36$

-Bean pod mottle virus, isolate diversity, 446

- Bean pod mottle virus and Soybean mosaic virus, in Nebraska, S141

-brown stem rot: crop rotation effect, S140; resistance, $\mathrm{S} 80$

- cyst nematode: classification test, S59; glyphosate tolerance, resistance, S29; hatching and $\mathrm{pH}, 456$; inbred lines, $\mathrm{S} 7$; peptides inhibiting secreted cellulase, S20; quantification, remote sensing, S140; soil pH effect, S56; stress and satellite images, S138; stress caused by, satellite images, S32

- disease resistance, use of markers, S8

- disease selection using DNA from seed, S137

- diseases and seed quality, fungicides, S151

- genes, defense-related, S31

- green leaf area index, radiometer use, S58

-management, SMART program, S148

-Meloidogyne incognita, cultivars in Illinois, S3

-microarrays, gene expression analysis, S106

-Phytophthora root rot, chitinase accumulation, S49

- Phytophthora sojae, races in Ohio and Indiana,
S39

-reniform nematode, cultivar response, S150

—rust, detection by PCR assay, 217

-Sclerotinia stem rot, Bayesian mapping, S102

- sudden death syndrome: on Delmarva, S151; root system characteristics, S61; tillage and variety effect, S152; tillage effect, S152

- systemic defense potentiation, S45

— transgenic, Round-up Ready gene, S139

-viruses, agronomic effect on, S139

Soybean dwarf virus, aphid vectors, in Illinois, $\mathrm{S} 34$

Soybean mosaic virus

-aphid immigration and soybean canopy, S46

- coat protein gene, transformed soybeans, 478

- glycophosate and imazamox effect, S45

- spatial and temporal dynamics, S140

Spaid, D. G., S150

Sparks, R., S8, S137

Spear, R. N., S53, S78

Species, definition and population, botryosphaerial mire, S95

Spencer, M., S51

Sphaeropsis sapinea, on Pinus nigra, detection in tissue, S26

Sphaerotheca macularis, on hop, infection risk, S100

Spilker, D. A., S38

Spilocaea pyracanthae, scab, formae speciales, 314

Spinach, leaf spot, Washington, S21

Spiroplasma kunkelii

— genome, DNA segment, S91

-transfer region characterization, $\mathrm{S} 5$

Spitko, R. A., S55, S78

Spore dispersal, splash droplet formation, hydrodynamics, S72

Spores, storage, petroleum jelly, S8

Spotts, R. A., S78

Squash, Phytophthora crown rot, fungicides, S74

Squash leaf curl virus, reassortant with related viruses, on cucurbits, 734

Squash yellow mottle virus, on cucurbits in Costa Rica, S125

Sreenivasaprasad, S., 986

St. Augustinegrass, gray leaf spot, resistance components and silicon, S148

St. Martin, S. K., S10, S11

Stachybotrys spp.

-S. chartarum, human health concerns, S93

$-S$. elegans, gene encoding chitinase, molecular cloning, S144

Stack, J. P., S106

Stack, R. W., S78, S139, S140

Stagonospora nodorum, on wheat

-seed infection, prediction using rainfall-based model, 511

-temperature sensitivity, S42

Stall, R. E., 273

Stall, W. M., S58

Standing, K., S74

Stanker, L., S21

Stanley, M. S., 378

Stanosz, G. R., S95

Stansbury, C. D., 321

St-Arnaud, M., S143

Starner, V. R., S80

Starr, J. L., S15

Statistics

-failure time analysis, epidemiology, S100

-multivariate, research use, S101

Stead, D. E., S110

Steadman, J. R., S3, S8, S64

Steddom, K., 850, 857, S10, S79

Stefani, E., S52

Stefanova, M., S134

Steffenson, B. J., 1064, S91

Steinlage, T. A., 478, S140

Stemphylium vesicarium, on pear, relative hu- 
midity and moisture effect, 99

Stenger, D. C., 734, S104

Stevens, C., S9, S79

Stevenson, K. L., S74, S79, S102, S152

Stevenson, W. R., S44, S70, S71, S105

Stewart, D. W., 534

Stienman, J., S85

Stierl, R., S4, S79

Stinson, A. M., S31

Stobbs, L. W., S13

Stockett, T. M., S43

Stockwell, V. O., 1202, S107

Stone, A. L., S29, S75

Stone, J. K., 112, S95

Stoneman, W. F., S105

Stowell, L. J., S52

Strausbaugh, C. A., S9

Strawberry

-anthracnose: histopathology, 1055; proteintransgenic strains, pathogenicity, 743

-black root rot: biocontrol agent, transplant root dips, S61; stramenopiles and pathogenicity, $\mathrm{S} 1$

-Botrytis cinerea, fungicides and resistance profiles, S153

-Botrytis fruit rot, yield variation, S50

- crown and fruit rot, population genetics of pathogen, 1245

— foliar diseases, spatial patterns, S59

— gray mold, flower tagging of infection, S37

-Messenger as growth enhancement, S67

-Pallidosis disease, Crinivirus, S82

- powdery mildew, risk model, S36

—rhizobacteria, soilborne pathogens, S34

- soilborne pathogens, remote sensing, S51

-soilborne pests, management and plasticulture system, S25

—Verticillium wilt, crop rotation, management, S40

- virus resistance, $\mathrm{S} 115$

Streptomyces spp.: cryptic plasmid, DNA sequence analysis, S16; culture collection, antibiotic and genetic characteristics, S17; on potato, pathogenicity region, $\mathrm{S} 85$

-S. scabies, on potato, soil moisture effect, S66

- S. setonii, endophytic, bioactivity, S16

-S. turgidscabies: nitric oxide synthase, thaxtomin biosynthesis, S84; nitric oxide synthase protein, characterization, $\mathrm{S} 11$; pathogenicity island, mobilizable, S41

Streptopus amplexifolius, virus detected in, Alaska, S69

Strobel, G. A., S31

Stromberg, E. L., S11, S142, S143

Sturbaum, A. K., S25

Stuteville, D. L., S138, S140

Stuthman, D., S12

Styer, W. E., 1167

Stylosanthes spp., Colletotrichum gloeosporioides, variation in Brazil, 553

Suárez, A., S135

Subbarao, K. V., 232, 631, S7, S40, S68, S88, S103

Subramanian, S., 273

Sudangrass, corn flea beetle, bacterial leaf blotch relation, $\mathrm{S} 82$

Sugar beet

-Aphanomyces root rot, biocontrol and induced resistance, $\mathrm{S} 55$

-Cercospora leaf spot: fungicides, S8; fungicides and biocontrol, management, S44; prediction model, S41; transformation with export gene, $\mathrm{S} 43$

-damping-off, biocontrol with Trichoderma, S33

-leaf spot, pathogen detection protocol, S45

—rhizomania, spectral properties, S79

— soilborne viruses, vector effect, S87

—-syndrome "basses richesses," phytoplasma and bacteria, 384

Sugar, D., 1202

Sugarcane

- cultivar resistance to diseases, S114

-Leifsonia xyli on, detection methods, S124

-nematode damage, suppressive soil, S69

-rust, defense response, S126

- smut, in Cuba, S125

-yellow leaf syndrome, phytoplasma, in Cuba, S115

Sukno, S. A., 1227, 1236

Sullivan, M. J., S79

Sun, X., 361

Sundin, G. W., S38, S79, S90

Sunflower

-Orobanche cumana on, resistance activated by benzothiadiazole, 59

- stem canker, molecular variability of pathogens, 308

Sunflower mosaic virus, host range and characterization, 694

Suppressive soil, Rhizoctonia solani on wheat, anastomosis groups 5 and 8, 1301

Sustainable disease control, 10,000 years of experience, S109

Sutton, T. B., S30, S35

Sutton, W., S30, S33, S54

Sutula, C. L., S34, S74, S111

Sweat, T. A., S104

Sweet cherry, powdery mildew, surface pitting, S78

Sweetingham, M. W., 1110

Sweetpotato, viruses, detection, S59

Sweigard, J., S7

Sycamore, leaf scorch, tolerance screening, S13

Sydorovych, O. B., S25

Symposia

—methyl bromide alternatives, deadlines, 1334 1375

- grape: black rot, epidemiology and management, 676; powdery mildew, resistance and disease management, 671

-Melhus graduate student, disease losses and management, 667

-Phytophthora capsici, spatiotemporal genetic structure, disease management, 681

Synchytrium endobioticum, on potato, soil assay, $\mathrm{S} 46$

Syngonium spp., Myrothecium leaf spot, resistance, S60

Sysak, R. W., S29

Szabo, L. J., S12, S79, S103

Tabor, G. M., S80

Takabayashi, N., 1182

Takamura, K., 1315

Takayama, Y., S41

Tal, M., 827

Talbot, M. M., S80

Talhinhas, P., 986

Taliaferro, C., S141

Tally, A., S108

Tang, X., S102, S138, S139, S141

Tans-Kersten, J., S3

Tapesia yallundae, T. acuformis comparison, mating type and apothecia, 703

Tapper, B. A., S62

Taylor, A. M., 1227, 1236

Taylor, E. L., 361

Taylor, G., S144

Taylor, J. D., 105, 1134

Taylor, S. E., S6

Taylor, T. V., S80

Teaching

—educational program specialist, S112

— graduate, on Internet, S112

-interactive television, S112

- online and residential instruction, S112

- online course to non-majors, S111
- science in non-major labs, S138

-web-based instruction standards, S112

Techniques, pythiaceous species from irrigation water, membrane filters, 610

Teixidó, N., 281

Tekauz, A., 710

Téllez Rodríguez, P., S132

Teni, R. E., S54

Tenuta, M., 255, 548

Teran, H., S133

Testa, A., S102

Thannhauser, T., S59

Theilmann, J., 87

Thibaud-Nissen, F., S106

Thies, J. A., S80

Thomas, C. S., S100

Thomas, G. J., 1110

Thomas, J. G., S148

Thomas, M. R., 553

Thomas, S. L., S80

Thomashow, L. S., S53

Thompson, C. M., S86

Thompson, D. C., S80, S112

Thompson, I. A., S80

Thomsen, I. M., S14

Thomson, K. C., S84

Thomson, S. V., S60

Thon, M. R., S80

Thrips spp.

-T. setosus, Tomato spotted wilt virus replication in, S4

-T. tabaci, Tomato spotted wilt virus vector, host preference and reproductive strategy, 603

Thurston, H. D., S109

Tian, Y., S81

Tiang, M., S102

Tiffany, L. H., S6

Tiffany, M. G., S111

Tilletia spp.

-T. controversa, new race, characterization, S30

-T. indica: teliospore sterilization, acidic electrolyzed water for, S142; on wheat, allee effect, invasive potential, letter to editor, 1152; on wheat, detection using PCR, S123; on wheat, establishment factors in Australia, 321

-T. maclaganii, on switchgrass, reactions, S140

-T. tritici, teliospore germination, pheromones, 210

Timmer, L. W., 794, 1267, S7, S15, S57, S64

Tisdell, R. H., S93

Tisserat, N. A., S38, S58, S75, S138, S141

Toapanta, M. A., S152

Tobacco

-black shank, race structure, variety rotation, S79

-blue mold: isolate genetic uniformity, 1236; necrotic response in leaves, S35; restriction fragment length polymorphism probes, contamination-free, 1227

-Tomato spotted wilt virus, rhizobacteria effect, $\mathrm{S} 150$

Tobacco mosaic virus

— gene silencing and resistance, S129

- systemic infection, S46

Tobacco ringspot virus

-nematode transmission, germ plasm screening, S28

— transmission by nematode, 646

Tobacco streak virus, on soybean, Wisconsin, S67

Tobias, D. J., S140

Todd, J. W., S51

Todd, T. C., S38, S58, S75

Tohamy, A. M., S81

Toledo, V., S127

Toledo Sampedro, V., S133

Tolin, S., 446

Tomato (see also Lycopersicon hirsutum) 
-bacterial canker, outbreak in California, S75

-bacterial leaf spot, bacteriophages for control, S108

—bacterial speck, biocontrol, 1284

-bacterial spot: bacteriophage and SAR inducers, S60; bacteriophage for control, S6; biocontrol and resistance inducers, in greenhouse, S60; neem oil and fish emulsion applications, $\mathrm{S} 1$

-begomovirus: on, detection in lines, S126; detection method, S121; genetic variability, S136; resistance in Guatemala, S54

-cDNA, lipid transfer protein homology, arachidonic acid, A1025

—damping-off, Monarda didyma effect, S31

—early blight, intercropping effect, S77

-Fusarium crown and root rot: biocontrol with Paenibacillus and Trichoderma spp., S118; compost-mediated induced resistance, 424

-Fusarium wilt: environment and biocontrol, 1160; Penicillium oxalicum as biocontrol agent, 863

-insects and diseases, monitoring in Nicaragua, S129

-late blight, protection by plant growth-promoting rhizobacteria, 1329; protection from peptide fusion, A1024

- leaf curl, begomovirus genomes, interspecies recombination, S38

- Pseudomonas syringae, induced cell death, S141

—southern blight: compost amendments, S49; soil factors and yield, 181

— spontaneous cell death, Pto overexpression, S139

—zebra-stem symptoms, Pto gene association, S69

Tomato leaf curl Karnataka virus, recombinant begovirus, India, 637

Tomato mosaic virus, diagnosis, in tomato and pimiento seed, Tobacco mosaic virus comparison, S121

Tomato ringspot virus, transmission by nematode, 646

Tomato spotted wilt virus

-glycoprotein, baculovirus expression, S86

-inoculation automation, S50

—nucleocapsid gene, introduced into peanut, S15

-on pepper, symptoms and resistance cultivars, S83

-recombinant protein, gen-n, S121

-replication in adult thrips, S4, 729

- transmission by thrips, efficiency, 603

Tomato yellow leaf curl virus

—on pepper in Cuba, S132

-tomato germ plasm resistance to whiteflytransmitted viruses in Guatemala, S127

- vector endosymbiosis, S96

-in whiteflies and reservoir hosts, 487

Tomato yellow leaf curl Sardinia virus

- comparison, detection, Morocco, S74

— genetic stability, in Spain, 842

Tomlinson, L., S68

Tonn, J. R., S36

Tooley, P. W., S81

Torres, A. M., 1262

Torres, D. B., S132

Torto, T. A., S102

Tosa, Y., 1182

Tourvieille de Labrouhe, D., 308

Tourvieille, J., 308

Towers, G., S146

Townley, A., S135

Tracy, M., S81

Trail, F., S31, S43

Tredway, L. P., S146, S152

Trent, M. A., S149

Trent, M. E., S91

Trently, D. J., S31
Trevathan, L. E., S135

Trichoderma spp., biocontrol agent, cotton damping-off, 177

-T. stromaticum: on Crinipellis perniciosa, mycoparasite on cacao, 1032; mycoparasite of Crinipellis perinicosa, nutrition, S72

Trichosporon pullulans, Botrytis cinerea conidia as vectors, 1293

Trick, H., S141

Trout, T. J., S10

Trout, T., 1349

Trouvelot, S., 936

Troxell, S. J., S28

Trujillo, G., S117

Trujillo, R., S131

Tsang, C., S76

Tsitsigiannis, D. I., S81

Tsror (Lahkim), L., 827

Tsukiboshi, T., S89

Tsushima, S., S89

Tsuyumu, S., S65, S89

Tubajika, K. M., S81

Tudor, S., S36

Tuffley, J. W., S82

Tumban, E., S82

Turechek, W. W., S19, S33, S100, S101

Turfgrass

-blight, trifloxystrobin for control, S38

- gray leaf spot on ryegrass and other hosts, 245, 1253

—rapid blight, new disease, S52

- snow mold, fungicides, S13

—-strobilurins, disease management, S111

-yeast populations, fungicides for S10

Turgeon, B. G., S93, S102

Turini, T. A., S82

Turnbull, G. D., S85

Turnip, Cercospora leaf spot, management alternatives, S149

Turnip mosaic virus

-on cabbage, internal necrotic spots, cover photo, August

- on white cabbage, relation to Beet western yellows virus and Cauliflower mosaic virus, internal disorders, 816

Tworkoski, T. J., S39

Tylka, G. L., S32, S80, S138, S140

Typhula spp.

— nuclear ribosomal DNA, internal transcribed spacer region, S56

-on wheat, geographical distribution in Wisconsin, S72

Tzanetakis, I. E., S52, S82

Uddin, W., 232, S82, S83

Uhm, J. Y., S37

Ullman, D. E., S86

Ullrich, M., S79

Upper, C. D., S96

Ureña-Padilla, A. R., 1245

Uromyces spp.

-U. appendiculatus: on bean, molecular markers and phenotype, S3; on bean, virulence distribution in field, 755; genetic diversity, AFLP analysis, S64

-U. viciae-fabae, on faba bean, resistance, histology, 294

Urs, R. R., S81

Usall, J., 281

Ustilago spp.

$-U$. hordei: mating and germination inhibitors, pheromone, S43; mating and pheromones, 210

-U. maydis: cuitlacoche yield from, pollination effect, S64; dimorphism, differential gene expression, $\mathrm{S} 27$

-U. scitaminea, on sugarcane: genetics and detection with PCR, S128; races in Cuba, S132; resistance mechanisms, S125

Uyemoto, J. K., S71
Vaiciunas, J. N., S146

Vaillancourt, L. J., 803, S26, S57

Valadez Moctezuma, E., S130

Valcárcel, M., S122

Valdés, S., S117, S122

Valdivia, O., S131

Valent, B., S7, S41

Valinsky, L., S82, S89

Vallejo, I., S82

Vallim, M. A., 1048

Van, K. P., S110

Vanamala, A., S83

van Berkum, P., S64

van Brouwershaven, I. R., 464

van Bruggen, A. H. C., 631

Van Camp, K. L., S145, S146

Van Cauwenberge, J. E., S73

Vandemark, G. J., 265

Van den Berg, P., S120

van den Boogert, P. H. J. F., S46

van den Heuvel, J. F. J. M., S96

van der Aa, H. A., 464

Van der Walt, E., 81

van der Wilk, F., S96

Van Driel, L., S13

van Es, H. M., S17

VanEtten, H. D., S70

Van Peteghem, P., 497

Van Roekel, J. W., S8

van Santen, E., S151

VanToai, T., S11

van Vuuren, S. P., S36

van Wijk, K. J., S59

Vargas, J. M., Jr., S22, S37

Varn, J., S80

Varveri, C., 563

Vasanthakumar, A., S83

Vautrin, S., 384

Vegetables, greenhouse pathogens, disinfectants, S13

Velázquez, K., S115

Velazquez-Monreal, J. J., S83

Vélez, H., S83

Venette, J., S18

Venturia inaequalis

-on apple: ascospore distribution in orchards,

769; on apple, ascospore production, leaf wetness, S145; on apple, genes of resistant locus, $\mathrm{S} 2$

-on apple and Pyracantha, two formae speciales, 314

Verchot-Lubicz, J., 347

Vereijssen, J., S83

Verhalen, L. M., 1323

Verissimo, P., S33

Verkley, G., 464

Verstappen, E. C. P., 439

Verticillium spp., on horseradish, root discoloration and control, S5

$-V$. dahliae: on lettuce, genetic analysis of resistance, $\mathrm{S} 7$; microsclerotia, ammonia and nitrous acid for destruction, 255; microsclerotia, destruction by liquid swine manure, 548; molecular basis of hosts, S68;

on strawberry, vegetative compatibility groups in California, S34; on wood chip mulch, source, S26

Vicente, J. G., 105, 1134

Vicia faba

-leaflet irradiation, glycoproteins, S38

-rust, resistance and histology, 294

Vick, C. M., S152

Vidaver, A. K., S2, S14

Vidavski, F., S54, S127

Vigil, M. E., S83

Viguié, A., 308

Viji, G., S82, S83

Vilchez, M., S129

Villanueva Verduzco, C., S127 
Viñas, I., 281

Vinokur, V., 393

Vintal, H., 164

Viruses

-chaperonin camouflage, S96

- diagnosis, heat treatment as tool, S44

- diagnosis in vegetables, grape, and citrus in Tunisia, S30

- geminivirus, resistance genes and phage display, S33

—gene silencing in protoplasts, S67

-Solanum bahamense as experimental host, $\mathrm{S} 2$

- survey on faba bean, lentil, and chickpea, in Egypt, S69

- transmission by nematodes, 646

- vector role, S104

- vector transmission, helpercomponent-transcomplementation, mini-review, 576

-vectors: agriculture and biotechnology, S105; vaccine components, S105

Vjugina, U., S89

Vodkin, L. O., S106

Vodrazka, K., S148

von Bodman, S. B., S57, S97

von Broembsen, S. L., S84

von Tiedemann, A., 145

Waalwijk, C., S30

Wach, M., S84

Wagner, A., S52

Wagner, E., S102

Walcott, R. R., S84, S149

Walk, T., 456

Walker, J. T., S84

Walker, N. R., S84, S88, S152, S153

Wall, G. C., S136

Wallace, L., S96

Walsh, J. A., 816

Walsh, K., S122

Walters, S. A., S3, S71

Wamishe, Y. A., S84

Wang, D., 1344

Wang, G. L., S39, S106

Wang, H., S85

Wang, J., S45, S59

Wang, K. N., S152

Wang, K.-H., S85

Wang, L., S85

Wang, P., S13

Wang, S. (Arkansas), 646

Wang, S. (China), 750

Wang, S.-Y. (California), S84

Wang, T. C., S143

Wang, X., S85

Wang, Y., 51, S151

Wang, Z., A1024

Wangsomboondee, T., 1189, S85

Wanner, L. A., S85

Ward, B. D., S148

Ward, L. J., S46

Ward, M. D., S111

Wardlaw, M. C., S148

Warnke, S., S17

Wasilwa, L., S61, S146

Wasson, J., S87

Watermelon

—bacterial diseases, in Illinois, S5

-Fusarium wilt, hairy vetch soil amendment, S91

—ozone injury, North Carolina, S37

-vine decline, nature and host specificity, S34

Watrud, L. S., 112

Watson, A. K., S142

Watson, M. E., S13

Website (see also Internet), plants, pathogens, and people, plant disease introduction, S22

Webb, C., S141

Webb, D. A., 497
Weber, A., S85

Weber, Z. W., S152

Wedge, D. E., S85, S153

Wegulo, S. N., S22, S29, S45, S87

Wei, Z.-M., S67

Weibel, E. N., S146

Weiland, J. J., S55

Weiss, B., 393

Welham, S. J., 497

Weller, D. M., 129, S53, S54

Weller, S. A., S110

Wells, L., S51, S149

Weng, Z., S86

West, D. R., S9

Westerdahl, B. B., S105

Wetzel, H. C., III, S6, S73

Weyant, R., S90

Weyman, P. D., A1025

Wharton, P. S., S86

Wheat

—biocontrol agent in rhizosphere, root architecture, S61

-bunt, teliospore germination and pheromones, 210

—common root rot, susceptibility, S140

- eyespot: residue burning and factors, S38; species, mating type, and apothecia, 703

- eyespot and Wheat streak mosaic virus, resistance, $\mathrm{S} 137$

-floral extracts, effect on Fusarium graminearum, $\mathrm{S} 23$

—foliar blight, rice-wheat systems in Asia, S109

- fungicide treatments, growth effect, S135

-Fusarium crown rot, damage in Pacific Northwest, S77

-Fusarium head blight: epidemic in Ohio, S23; epidemiology, S93; freeze-drying protocol for antagonist, S73; inoculation timing, mycotoxin, severity, S24; resistance genes and chromosome location, S78; stem rust resistance, S139

-head blight and crown rot in Australia, S2

- Karnal bunt: allee effect and invasive potential, letter to editor, 1152; establishment factors in Australia, 321

-leaf rust: seedling and adult-plant resistance genes, S84; uredospore production, carbon and nitrogen relation to lesion size and density, 762

-leaf and stripe rust, infection efficiency, light effect, 1308

-Magnaporthe grisea, gene-for-gene relation, 1182

-Mycosphaerella graminicola: on, isolate aggressiveness in cultivars, 624; sexual reproduction frequency effect, 1175

- pseudomonad association, fluorescent, S27

—Rhizoctonia solani, soil suppressiveness, S53

-root-lesion nematode, semiarid environment, S77

-root pathogens, severity, on barley, Idaho, S9

- Septoria tritici blotch: cultivar mixture effect, 617; gene-for-gene relation, 439

-Septoria tritici leaf blotch, resistance and molecular mapping, S2

-Soilborne wheat mosaic virus, inoculation methods, 347

-stripe rust: in Asia, S88; resistance and markers for detection, S14

-take-all: biocontrol, S54; detection using PCR, S143; gene expression in roots, S140; management factors in Arkansas, S56; ribosomal DNA phylogeny, S26

- $\tan$ spot: host-selected toxin, 38; toxin and resistance gene, 527; toxin from new race, S3

Wheat streak mosaic virus, vector gene expression, S104

Wheeler, T. A., S72

Whistler, C. A., S86

White, D. C., S49
White, D. G., S53

White, F. F., S138

White, J. H., S21, S28

Whitfield, A. E., S86

Whittaker, G., S65

Wichman, R. L., S86

Wick, R. L., S144, S147

Wickert, E., S86

Wickizer, S. L., 646, S28

Widders, I., S4

Widholm, J., S47

Widstrom, N. W., S149

Wiecko, A. T., S136

Wilcox, W. F., 676, 1068, S41, S91

Wilhelm, S, 1349

Wilkinson, H. T., S26

Williams, H., S57

Williams, M. G., S86

Williams, W. P., S87

Williamson, J. D., S83

Williams-Woodward, J. L., S58

Willie, K., S14

Willment, J. A., 81

Wilson, A. D., S87

Wilson, C. L., 900, S9

Wilson, C. R., S101

Wilson, D. M., S87, S149

Wilson, J., S29, S87

Wilson, L. L., S23

Wilson, M. (Colorado), 1284, 1329

Wilson, M. A. (Missouri), S9, S79

Windels, C. E., S9, S22

Windham, G. L., S87

Wing, R., S39

Winkler, V. W., S55, S87

Wintermantel, W. M., S87

Winton, L. M., 112, S95

Wise, K. A., S87

Wishart, J., 884

Wisler, G. C., S87

Wolf, T. K., S142

Woloshuk, C. P., S8, S25, S37

Wolpert, T. J., S104

Wolyn, D. J., S35

Wong, F. P., S73

Wong, M.-Y., S87

Wong, S.-M., 654

Wood decay, oxalic acid and $\mathrm{pH}$ in cultures, S73

Wood, P., S76

Woodward, J. E., S88, S153

Workneh, F., 659, 1026, S10

Wright, K., S111

Wu, B. M., 631, S88

Wu, J., S102

Wu, Y. X., 145

$\mathrm{Wu}, \mathrm{Z} ., 87$

Wynia, R. L., S140

Xanthomonas spp.: avirulence genes, analysis, S65; Dasheen mosaic virus on, immunization, S120; on golf greens, Northeast USA and Canada, S10; on pepper, hypersensitivity, 273; phylogenetic marker, heat-shock gene, S51; on tomato and pepper, neem oil and fish emulsion applications, S1

$-X$. albilineans: genetic diversity in Cuba, S118; serological diversity, in Cuba, S130

$-X$. arboricola, on prune, detection with PCR primer and DNA probe, $\mathrm{S} 62$

-X. axonopodis: on bean, resistance, cultivar, S117; on bean, strain diversity, S50; on citrus, clonal population in Brazil, S12; on citrus, epidemic in Florida, analysis, 361; on citrus, pathogenic strains, S128; on citrus, strains in Argentina, S116; on citrus, survival in lesions and inoculum dispersal, 336; on Medicago truncatula, stunting in accessions, S138; on pepper, hypersensitivity and temperature, 197; 
selection pressure on non-functional to functional genes, S85

-X. campestris: antagonism by Bacillus, S66; on anthurium, beneficial bacteria, $\mathrm{S} 4$; bacteriocin antagonistic to, S36; on Brassica spp., homologues and elicitors, S65; on Brassica spp., race-specific resistance inheritance, 1134; on Brassica spp., resistance sources and origin, 105; on cabbage, resistance and ultraviolet light seed treatment, S9; cercosporin detoxification, S80; on cotton, near-isogenic lines for resistance, 1323; virulence and extracellular polysaccharide, S66

$-X$. citri, on citrus, strain characterization, molecular, S3

$-X$. fragariae, on strawberry, resistance, S49

$-X$. oryzae, on rice, resistance and gene mapping, 750

Xiangmin, L., S110

Xiao, C. L., S34, S50, S88

Xiao, F., S141

Xie, W., 87, S1

Xiong, Z., S86

Xiphinema americanum, virus vector, localization, 646

Xu, J. R., S31, S42, S47, S63, S81

$\mathrm{Xu}, \mathrm{R} ., \mathrm{S} 19$

Xu, X.-M., 1005

$\mathrm{Xu}, \mathrm{Y} ., \mathrm{S} 88$

Xue, A. G., S90

Xue, C. Y., S47

Xylella fastidiosa

-on almond, transmission by leafhopper sharpshooters, S3

-biofilm and planktonic populations, quantification, S51

- cell wall degrading enzyme, in grapevine xylem sap, S70

-on citrus: quantification by PCR assay, 1048

-on citrus and coffee, genotyping, in Brazil, S86

-on grape: one-hour diagnosis using PCR, 721; survey in Georgia, S9; citrus, and mulberry, evolutionary perspective, S14

- pathogenicity factors, gene profile, S36

- protein related to chlorosis on Chenopodium quinoa, S10 -strain variation, S86

- terpene effect on growth, S13

- transformation, replicative shuttle vector, $\mathrm{S} 83$

Yabor, L., S120

Yahyaoui, A. H., S88

Yakoby, N., 1196

Yamaguchi, I., 75

Yamak, F., 1210

Yamato, M., S88

Yan, G. P., S14

Yan, Z., 1329

Yanez, V. R., S24

Yang, H. A., 1110

Yang, J., 51

Yang, X. B., S56, S100, S101, S102

Yang, Y., 870

Yang, Z. N., S36

Yap, M.-N., S88

Yassi, M. N., S89

Yates, S. R., 1344

Yellow dwarf virus, on grain crops, quantification, $\mathrm{S} 5$

Yike, I., S93

Yin, B., S89

Ying, Z., S18

Yoder, K. S., S108, S147

Yoder, O. C., S102

Yoon, J. Y., 156

Yoshida, S., S89

Young, D. H., S53, S89

Young, N. D., S106

Ypema, H. L., S4, S6, S73, S89

Ytterberg, J. A., S59

Yu, I.-C., S103

Yu, M., S47

Yu, Y., S39

Yuan, C., S89

Yuan, R., S15

Yuen, G., S91

Yuen, J. E., S100

Yuen, J. M. F., S60

Yun, S.-H., S93

Zablotowicz, R. M., S1

Zambino, P. J., S36, S95
Zandstra, B., S4

Zapote-Martínez, C. A., S123

Zchori-Fein, E., S96

Zeller, W., S115

Zeng, H. C., S89

Zerbini, F. M., 563

Zernova, O., S47

Zhan, J., 946

Zhang, C., S32

Zhang, G., S30

Zhang, H. (Oklahoma), S88

Zhang, H. B. (Texas), 417

Zhang, J. (Ohio), S90

Zhang, J. X. (Canada), S90

Zhang, N., 1276

Zhang, Q., 750, S90

Zhang, R., S90, S147

Zhang, S., S90

Zhang, X., S90

Zhang, Y. (Oklahoma), S141

Zhang, Y. (Wisconsin), S91

Zhang, Y. P. (California), S71

Zhang, Z., S116

Zhao, A., A1025

Zhao, X., S18

Zhao, Y. (Maryland), S91, S105

Zhao, Y. F. (Oklahoma), S91

Zheng, F. C., S89

Zhong, S., S91

Zhou, B., S39

Zhou, J.-M., S91, S139, S138, S141

Zhou, S., S95

Zhou, X. G., S91

Zhu, H., S19

Zhu, L., 917

Zhu, T., S102

Zidack, N. K., S6, S31

Ziegler-Graff, V., S96

Ziems, A. D., S29, S141

Zimmerman, M. D., S40

Zitter, S. M., S91

Zitter, T. A., 997, S62

Zucchini green mottle mosaic virus, on cucurbits, transcripts, genome structure, 156

Zveibil, A., 164

Zwiesler-Vollick, J., S92 